\title{
ECLIPSES DE CUANDO ÉRAMOS CHICOS: RECUERDOS VIVENCIALMENTE SIGNIFICATIVOS DE ECLIPSES DE SOL
}

\author{
Néstor Camino ${ }^{1}$ \\ Santiago Paolantonio ${ }^{2}$
}

\begin{abstract}
Resumen: Desarrollamos un estudio cualitativo interpretativo con adultos mayores de 65 años, relevando sus recuerdos sobre eclipses de Sol vistos cuando eran chicos, entre 1921 y 1960 (18 parciales, 4 anulares y 3 totales). Buscamos corroborar si las experiencias "vivencialmente significativas" de cuando chicos, en este caso: la visualización de eclipses de Sol, pueden ser recuperadas décadas después a través de los recuerdos, con un buen grado de correspondencia con el fenómeno ocurrido. Los registros se obtuvieron solicitando la descripción del recuerdo, la edad que tenían, en qué época y lugar y con quiénes lo vieron, y cómo se enteraron de la ocurrencia del fenómeno. El estudio se desarrolló durante varios años a través de entrevistas personales y cuestionarios escritos; la participación de los adultos mayores fue voluntaria. Con aquellos recuerdos cuyo relato espacio-temporal así lo permitiera, identificamos cuál habría sido el eclipse observado, ubicándose además en el mapa de Argentina quiénes y desde dónde vieron el mismo eclipse. Nuestro objetivo es brindar nuevos elementos para fundamentar una Enseñanza de la Astronomía que no sólo tienda a la construcción de aprendizajes significativos en general, sino también a generar experiencias de vida, vivencialmente significativas para las personas y socialmente relevantes para todos.
\end{abstract}

Palabras clave: Eclipses de Sol; Recuerdos; Vivencialmente significativo; Enseñanza de la Astronomía.

\section{ECLIPSES DE QUANDO ÉRAMOS CRIANÇAS: MEMÓRIAS VIVENCIALMENTE SIGNIFICATIVAS DE ECLIPSES DO SOL}

Resumo: Desenvolvemos um estudo interpretativo qualitativo com adultos com mais de 65 anos, recuperando suas lembranças de eclipses solares vistos quando meninos entre 1921 e 1960 (18 parciais, 4 anulares e 3 totais). Buscamos corroborar se as experiências "vivencialmente significativas" das crianças, neste caso: a visualização dos eclipses do Sol, podem ser recuperadas décadas mais tarde através de memórias, com um bom grau de correspondência com o fenômeno. Os registros foram obtidos solicitando a descrição da memória, a idade que eles tinham, a que hora e lugar e com quem eles viram, e como eles aprenderam sobre a ocorrência do fenômeno. $\mathrm{O}$ estudo foi desenvolvido ao longo de vários anos através de entrevistas pessoais e questionários escritos; A participação de adultos mais velhos foi voluntária. Com as lembranças que a história do espaço-tempo permitiu, identificamos o que teria sido o eclipse observado, também localizando no mapa da Argentina quem e de onde outros viram o mesmo eclipse. Nosso objetivo é fornecer novos elementos para apoiar um Ensino de Astronomia que não só tende a construção de aprendizagem significativa em geral, mas também para gerar experiências de vida que sejam significativas para pessoas e socialmente relevantes para todos.

Palavras-chave: Eclipses solares; Memórias; Vivencialmente significativo; Ensino da Astronomia.

\section{ECLIPSES OF THE TIME WHEN WE WHERE KIDS: VIVENTIALLY MEANINGFUL MEMORIES OF SOLAR ECLIPSES}

\footnotetext{
Abstract: We developed a qualitative interpretative study with adults older than 65, about their memories of when they were kids, associated with solar eclipses that occurred between 1921 and 1960 (18 partial, 4 annular and 3 total). We seek to corroborate whether the "experientially meaningful" experiences of

${ }^{1}$ Complejo Plaza del Cielo - CONICET-FHCS (UNPSJB). Esquel, Argentina.

E-mail:<nestor.camino@speedy.com.ar>.

${ }^{2}$ Observatorio Astronómico de Córdoba - Museo Astronómico, Córdoba, Argentina.
} 
childhood, in this case: the visualization of Sun eclipses, can be recovered decades later through memories, with a good degree of correspondence with the phenomenon occurred. Records were obtained requesting the description of the memory, the age they had, at what time and place and with whom they saw it, and how they learned of the occurrence of the phenomenon. The study was developed over several years through personal interviews and written questionnaires; the participation of older adults was voluntary. With those memories whose space-time story allowed it, we identified what would have been the observed eclipse, also located on the map of Argentina who and from where they saw the same eclipse. Our objective is to provide new elements to support an Astronomy Teaching that not only tends to the construction of meaningful learning in general, but also to generate life experiences that are meaningful for people and socially relevant for all.

Keywords: Solar eclipses; Memories; Viventially meaningful; Astronomy Teaching.

\section{Introducción}

"De un tiempo perdido a esta parte esta noche ha venido un recuerdo encontrado para quedarse conmigo"

Andrés Calamaro, "Para no olvidar".

Los eclipses de Sol han sido fenómenos de alto impacto sobre las personas y las comunidades, a través de la Historia y en todo el planeta. Asimismo, el estudio de los eclipses fue uno de los campos del conocimiento más desafiantes para la construcción de explicaciones y predicciones sobre el mundo natural astronómico, en íntima relación con las necesidades y preguntas de las diversas sociedades humanas: desde los registros sistemáticos de observaciones de miles de años atrás hasta la potencia predictiva de las teorías y herramientas tecnológicas del presente, los eclipses han sido quizás los eventos más significativos en cuanto a la comprensión del funcionamiento del universo en función de lo que percibimos los seres humanos que somos parte del mismo, y de las concepciones filosóficas, creencias y modelos construidos a través de los siglos.

¿Qué importancia se les ha dado a los eclipses solares en la educación, y especialmente qué importancia se les da hoy? Lamentablemente, muy poca, o al menos podríamos afirmar que el lugar que se les da no remite a la trascendencia que hemos mencionado antes: el estudio de los eclipses en general casi ha desaparecido de la vida escolar, estando en el mejor de los casos reducida a unas pocas imágenes sobre el pizarrón con alguna relación geométrica, a mostrar alguna simulación o modelo concreto (en general deficientes) y a contar algunos mitos e hitos históricos, en muchos casos presentados como rarezas. Más aún, la vivencia de estos fenómenos por parte de la gente, especialmente de los más chicos, ha disminuido sustancialmente. Muy pocos son quienes se emocionan, se conmueven, por haber vivido el proceso que incluye observar, imaginar, comprender, estudiar, sentir, en el orden que fuera, algún eclipse de Sol en su vida. Tal situación (de pérdida) es grave desde muchos aspectos, siendo el antropológico quizás el más notable a los fines de nuestro estudio.

Hace más de diez años, durante el desarrollo del "Proyecto Chiron: el cielo patagónico para los abuelos de Esquel" (CAMINO, 2009), surgieron nuestros primeros encuentros con los recuerdos que tenían aquellos viejos con los que trabajamos sobre los eclipses que habían visto cuando chicos. Chiron estuvo dedicado al trabajo colaborativo y vivencial con adultos mayores de 65 años, mediante reuniones semanales, con tres implementaciones de al menos dos años de duración cada una, con 
fuerte carga observacional de todos los fenómenos astronómicos de la época (eclipses de Sol y de Luna, cometas, tránsito de Mercurio, equinoccios y solsticios, entre otros). Durante esas reuniones de intenso trabajo, en especial cuando se observaba algunos de los fenómenos antes indicados, estaban invitados los nietos y familias de los adultos mayores. En charlas y discusiones con varias generaciones involucradas, surgieron muchos recuerdos, y allí a su vez surgió la idea para este trabajo.

Fue nuestra experiencia y es nuestra convicción que el valor de la observación de un eclipse de Sol, ya sea contemplativa o como parte de un estudio intencional, excede sustancialmente los fines educativos de transmitir conceptos astronómicos "puros". Tal acción fortalece la trama social de nuestra comunidad integrando no sólo al mundo natural astronómico a la cotidianeidad de nuestras vidas, sino también al conocimiento científico y a evolución histórica de las ideas, en una forma más genuina que aquella a la que nos hemos acostumbrado todos, especialmente los educadores, dentro de las instituciones educativas. Presentaremos a continuación el trabajo realizado, sus resultados y conclusiones.

\section{Los eclipses de Sol como fenómenos naturales y sociales}

Es importante tener en cuenta que, en general, los eclipses de Sol no son visibles "casualmente" (a menos que ocurra un eclipse total y se vea desde donde estamos, sorprendiéndonos, lo que es una situación muy rara).

De acuerdo con Henige (1976, citando a Robert Newton, "Ancient astronomical observations and the acceleration of the earth and moon", Baltimore, 1970), un observador desprevenido probablemente no se daría cuenta de la ocurrencia de un eclipse de magnitud menor a 0,90 (la magnitud de un eclipse solar indica cuánto del diámetro del Sol será cubierto por la Luna en el máximo del eclipse). De hecho, tal observador notaría algo inusual sólo en un eclipse de magnitud de 0,95, si las condiciones del tiempo atmosférico fueran tan buenas que permitieran notar la disminución de la luz ambiente (el efecto quizás más notorio a nivel general); de todos modos, aunque el observador desprevenido notara este efecto, es probable que no pudiera darse cuenta de qué lo produce (incluyendo esto a la disminución de la temperatura ambiente en un eclipse de Sol de gran magnitud). Por otra parte, un observador preparado y a la espera de un eclipse solar, podría detectar uno de magnitud de 0,75. Hay otros indicadores de la ocurrencia de un eclipse de Sol, como las imágenes proyectadas sobre el suelo, producidas por los intersticios entre las hojas de los árboles que actúan a modo de cámara oscura, pero sería aún más "casual” notar este efecto que el cambio en la luminosidad ambiente (coloración, sombras difusas, etc.). Henige (op. cit., p. 479) afirma, citando nuevamente a Newton, que muchos de los eclipses de baja magnitud registrados en la Historia fueron calculados y no observados casualmente.

Es decir, para haber vivido un eclipse solar, lo más probable es que nos hayamos enterado antes por algún medio. La observación de un eclipse solar es, en buena medida, un hecho social: se lo observa casi siempre si a través de otros nos hemos enterado del mismo, y en general se lo observa con otros, mucho más si los protagonistas son chicos, como lo fueron en su momento quienes nos han brindado sus recuerdos, ya adultos mayores. 
Los registros que hemos obtenido no remiten únicamente al hecho físico, astronómico, de un eclipse solar, sino que vinculan esa experiencia con abuelos, padres, hermanos, amigos, maestros, en un determinado lugar, durante un cierto tiempo. Compartir la experiencia directa de observar un eclipse de Sol en compañía de otros es lo que transforma a una información recogida a través de los Medios o a través de un comentario realizado en un aula en una experiencia vivencialmente significativa que será recordada durante toda la vida.

Así, la trascendencia de observar un eclipse solar (como también cualquier otro fenómeno astronómico, por quedarnos en el contexto de nuestra propia especialidad) se dimensiona si tomamos en cuenta ambos aspectos: qué características tenía el eclipse en cuestión como hecho astronómico (el cual habría ocurrido de todos modos, aunque la Tierra estuviera deshabitada), y qué significatividad tuvo para el observador en su momento vital y en su propio contexto social.

\section{Recuperar los recuerdos de los más viejos sobre eclipses}

¿Qué tan significativa desde lo vivencial habrá sido hace décadas, para aquellos chicos, la observación de un eclipse de Sol? Una forma de comprenderlo es a través de recuperar sus recuerdos, asociados a cuando cada quién visualizó un eclipse solar, en la época actual cuando todos ellos ya son viejos.

La hipótesis de trabajo, entonces, es muy simple: si una experiencia de vida fue significativa (por las razones que fueran), será posible recuperarla a través del relato de un recuerdo, el cual debería tener algún tipo de vinculación con la realidad del hecho físico vivido (en este caso un eclipse de Sol), a pesar del tiempo transcurrido (décadas, en el caso del presente estudio), y evidenciar elementos de fuerte carga social y afectiva (BALLARINI, 2014).

Es decir, concretamente, buscaremos con este trabajo relevar recuerdos de adultos mayores, con edades que van desde pasados los 60 años hasta cerca de los 100 años, asociados a cuando eran chicos, con edades entre 6 años y como máximo cerca de los 20 años, sobre eclipses de Sol ocurridos y posibles de haber sido vistos en nuestro país entre los años 1921 y 1960 (para la justificación del rango temporal, ver punto 4.).

Cabe destacar que no se busca relevar con este trabajo la ocurrencia de los eventos naturales que denominamos eclipses de Sol de un modo objetivo, físico, ya que los mismos son tomados como datos concretos, conocidos con total precisión (ver las referencias a las páginas web sobre eclipses de la NASA). Por el contrario, lo que buscamos es recuperar los recuerdos, las sensaciones, de quienes, quizás, hayan vivido tales eventos cuando eran chicos o adolescentes, con el fin de comprender qué han conservado vivo de aquellas vivencias más de medio siglo después.

Es muy importante tener en cuenta que, con el tiempo, luego de décadas de vida, los recuerdos pueden modificarse, de muy diferentes y sutiles maneras (se pueden incorporar elementos ficticios, o algunos no vividos personalmente sino por otras personas cercanas afectivamente, entre otros factores (IGOA, 2004).

Por esta razón, hemos buscado la correspondencia del recuerdo relatado con el hecho físico al que podría estar vinculado: hemos hecho énfasis entonces en identificar en sus recuerdos qué elementos remiten a un hecho físico concreto (un tipo de eclipse 
de Sol, en un cierto momento, visto desde una posición topocéntrica particular) vivido por ellos, y recordado al paso de las décadas, pero no hemos profundizado en aquellos elementos que pudieran haber sido tomados o incorporados inconscientemente de otras experiencias, de diarios, de diálogos, etc., e integrados a los recuerdos hoy recuperados.

Para intentar discriminar lo antes expuesto, es indispensable sumar al análisis de los recuerdos la contrastación con el camino sobre la superficie terrestre de cada eclipse visto desde Argentina en ese período, conocer la forma en que cada entrevistado recuerda haberse enterado y si fuera posible recuperar de qué manera lo visualizaron, ya que ningún eclipse (excepto los pocos minutos de uno total) son visibles a ojo desnudo, lo que requiere de utilizar algún dispositivo tecnológico (p. ej., un vidrio ahumado).

El registro de los recuerdos nos brinda la posibilidad de recuperar detalles, minuciosos quizás, idiosincrásicos siempre, que de otra manera no tendríamos siquiera dato alguno, serían inaccesibles, perdidos para siempre en el tiempo y en las vidas de aquellas personas que vivieron eventos astronómicos únicos.

Estos detalles, que también son parte de la Astronomía, no pueden conocerse a través del estudio de los mapas de eclipses, sino que surgen de un proceso de investigación como el presente.

En síntesis, nos interesa recuperar las vivencias cuando chicos de personas vivas, con quienes hemos podido conversar y comunicarnos con motivo de recordar un eclipse de Sol. No nos interesa contar una historia inocua de un hecho físico, sino que nos motiva recuperar sensaciones, imágenes, de personas concretas que vivieron un fenómeno que, en todos los casos, fue impactante para quienes ellos eran entonces: chicos. Hemos elegido entonces trabajar con recuerdos personales, una de las fuentes más importantes del trabajo con la historia oral, ya que según Prins (1993) los recuerdos son evidencia oral específica basada en las experiencias propias del informante.

\section{La selección del período de tiempo}

Definir un rango de fechas para un estudio como el presente requiere definir algunos criterios, los cuales siempre son relativos y también subjetivos, como lo son especialmente en este caso.

Tomar el inicio del estudio a partir de 1921 se fundamenta en la posibilidad de encontrar aún adultos mayores con capacidad para contar algunos detalles de sus recuerdos cuando niños. Vale decir que desde cuando iniciamos este estudio, en 2004 aproximadamente, y hasta la fecha, los informantes más longevos que hemos podido entrevistar habían nacido en la década de 1920 a 1930, no antes.

Tomar el final del estudio en el año 1960 se fundamenta en que buscamos relevar recuerdos lo más "genuinos" posibles, "genuinos" en el sentido de que los mismos estén vinculados a una vivencia de observación directa. Es decir, podría suceder que alguien recuerde un eclipse de Sol a partir de una información vista por televisión, como es muy habitual en estos tiempos modernos, y no por haberlo visto él mismo. La televisión, como fuente de información, pero fundamentalmente como productora de imágenes, sólo comenzó a difundirse por el interior de Argentina bien entrada la década del 1960. Se considera que la televisión en Argentina comenzó cuando el 17 de octubre de 1951 inicia su emisión LR3 Radio Belgrano TV, por el canal 7; ya en noviembre su 
señal era recibida por unos pocos televisores en una pequeña área de $5 \mathrm{~km}^{2}$ en el centro de la ciudad de Buenos Aires. Para la emisión y recepción de televisión abierta hacia el interior de nuestro país hubo que esperar más de una década, bien entrados en los años '60, y más tarde aún en la Patagonia. Así, podemos estar relativamente seguros que los adultos mayores que nos han compartido sus recuerdos de haber observado algún eclipse de Sol cuando chicos lo hicieron mirando el cielo real y no a través de una pantalla de televisión.

\section{La información sobre eclipses en los Medios de la época}

Por lo antes expuesto, es posible afirmar que las fuentes de información de aquella época entre 1921 y 1960 fueron, principalmente, la radio y los medios de comunicación gráficos. Pero ubicándonos en el interior de nuestro país, regiones de las que provienen la mayoría de los adultos mayores que hemos entrevistado para el presente estudio, lo habitual era que se escuchaba radio, AM, y en esta frecuencia en general las distintas emisoras de Radio Nacional.

Los medios gráficos de la Capital eran o bien "raros" o bien "un lujo", y en general siempre llegaban al interior días después de haber sido impresos. A su vez, la fuente de información de los diarios locales, si los había, era la radio, recibida con dificultad, dados las distancias y los medios técnicos de la época, y seguramente el telégrafo, medio confiable y de gran disponibilidad en todo el país.

La gran mayoría de los adultos mayores entrevistados recuerda que las principales fuentes de información sobre los eclipses fueron las noticias que su familia escuchaba por la radio, o sus maestros en las escuelas (quienes seguramente también escuchaban la radio). Son pocos quienes suponen que la fuente de información fue un diario impreso, y estos son quienes cuando chicos vivían en ciudades, ya no en el interior de la extensa geografía argentina.

En los grandes centros (Buenos Aires, Córdoba, principalmente) la información en los medios gráficos era de todos modos poca, pero existía (Figuras 1 a 4). En Esquel y la región noroeste del Chubut (ORIOLA, 2017), el periodismo escrito nace en 1924 (semanario El Libre del Sur, hasta 1950) y en 1925 (semanario Esquel, diario a partir de 1945, hasta la década del '60). En ninguno de estos medios gráficos figuran noticias previas a los eclipses de 1947 y 1952, existiendo únicamente una breve mención el día siguiente al eclipse de 1952 (Figura 3). En esta región, aún años después, los diarios de Buenos Aires o bien no se recibían o, más hacia los años '60 y '70, llegaban con varios días de atraso. En cuanto a la radiodifusión, recién en noviembre de 1961 comenzó a emitir LRA9 Radio Nacional Esquel (la primera Radio Nacional en Patagonia Sur); las primeras FM hacen su aparición recién en los años '80. 


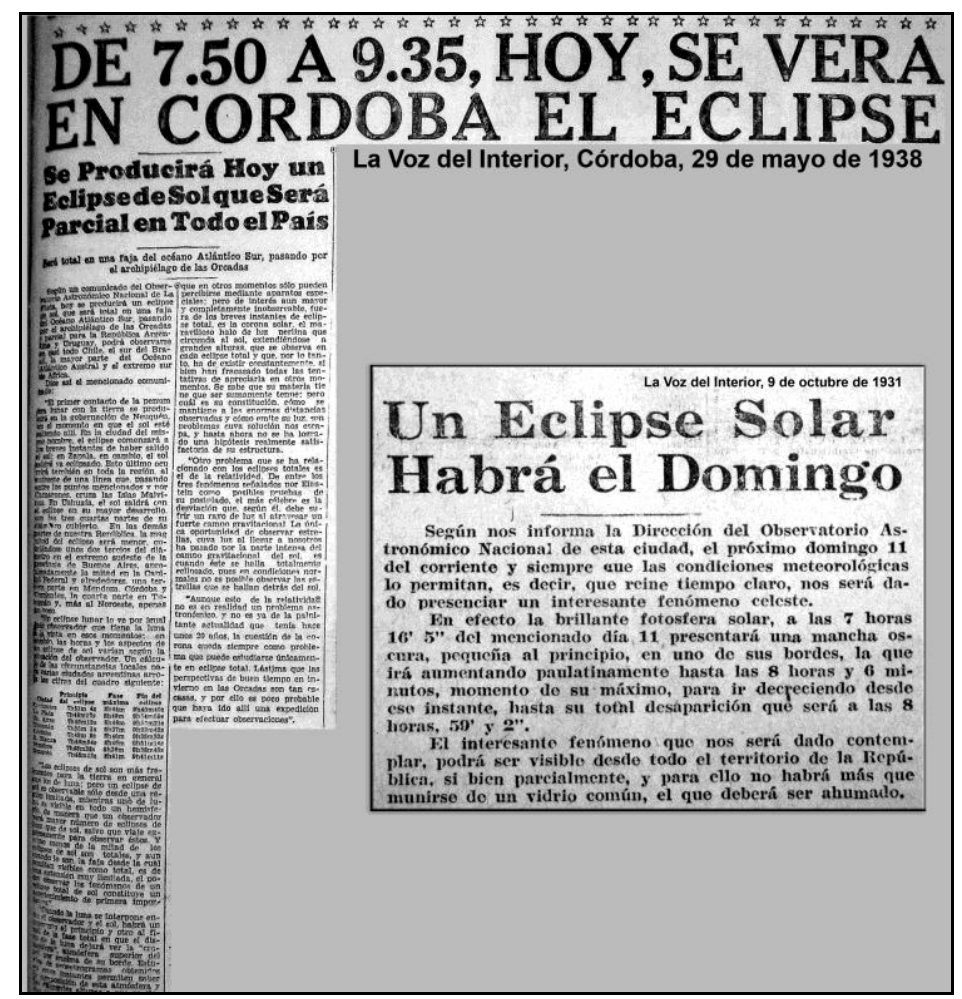

Figura 1 - Notas en el diario La Voz del Interior, de Córdoba, sobre los eclipses de 1931 y 1938.

Fuente: Hemeroteca Legislatura de la Provincia de Córdoba.

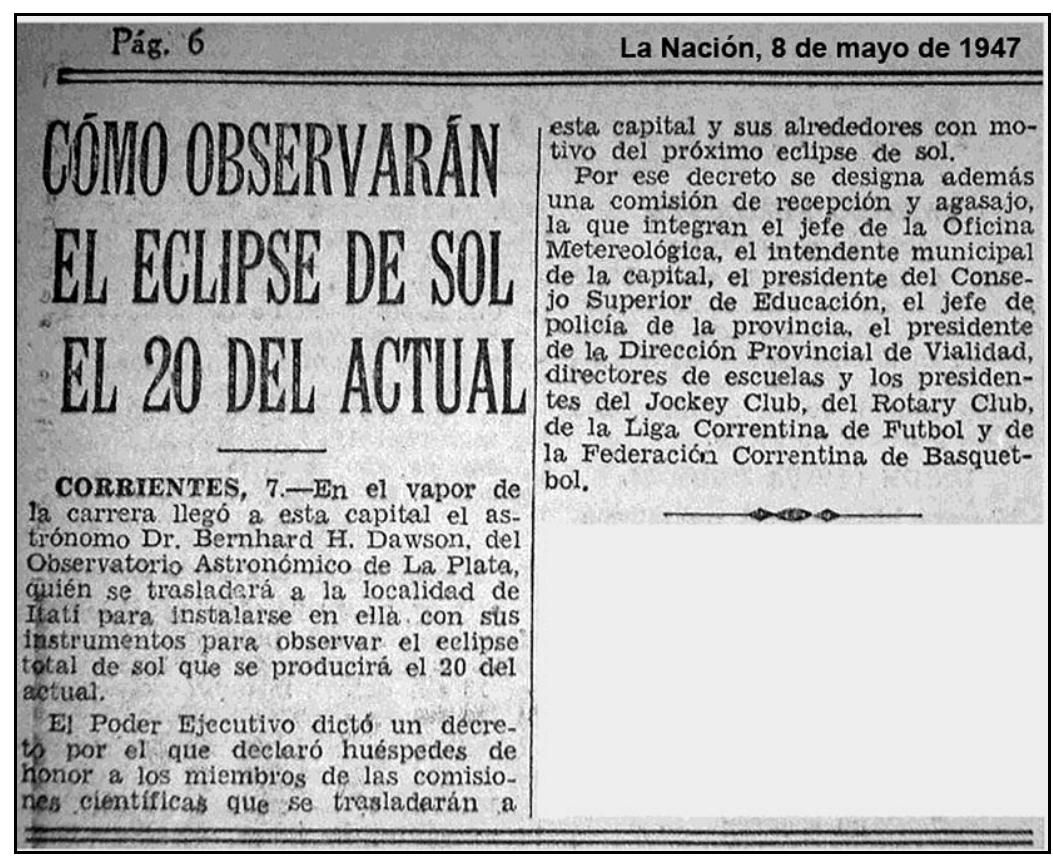

Figura 2 - Nota en el diario La Nación, de Capital Federal, sobre el eclipse de 1947. Fuente: Biblioteca Observatorio Astronómico Córdoba. 


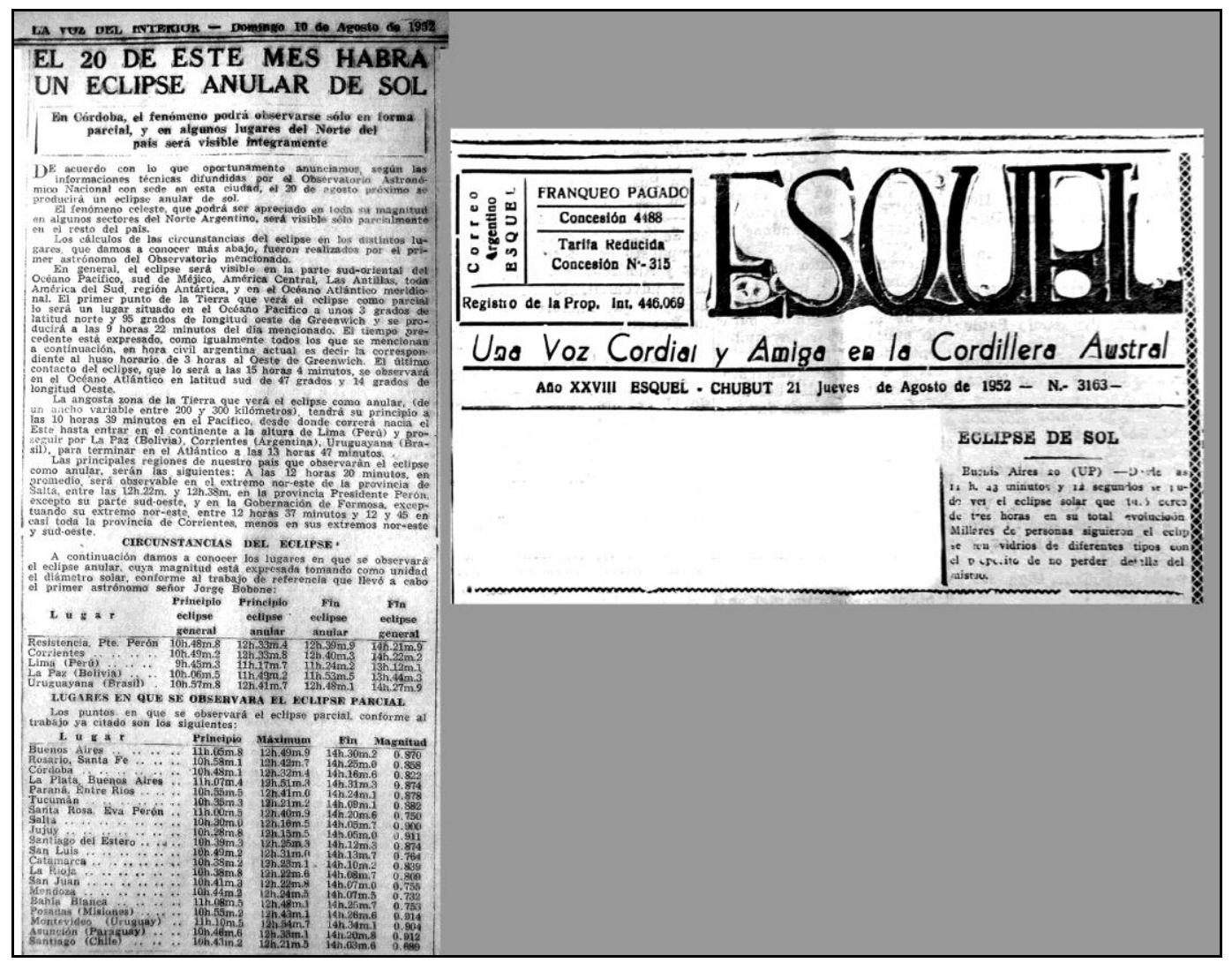

Figura 3 - Nota en el diario La Voz del Interior, de Córdoba, y en el diario Esquel, de Esquel, sobre el eclipse de 1952.

Fuentes: Hemeroteca Legislatura de la Provincia de Córdoba y Archivo Histórico Municipal de Esquel, respectivamente. 


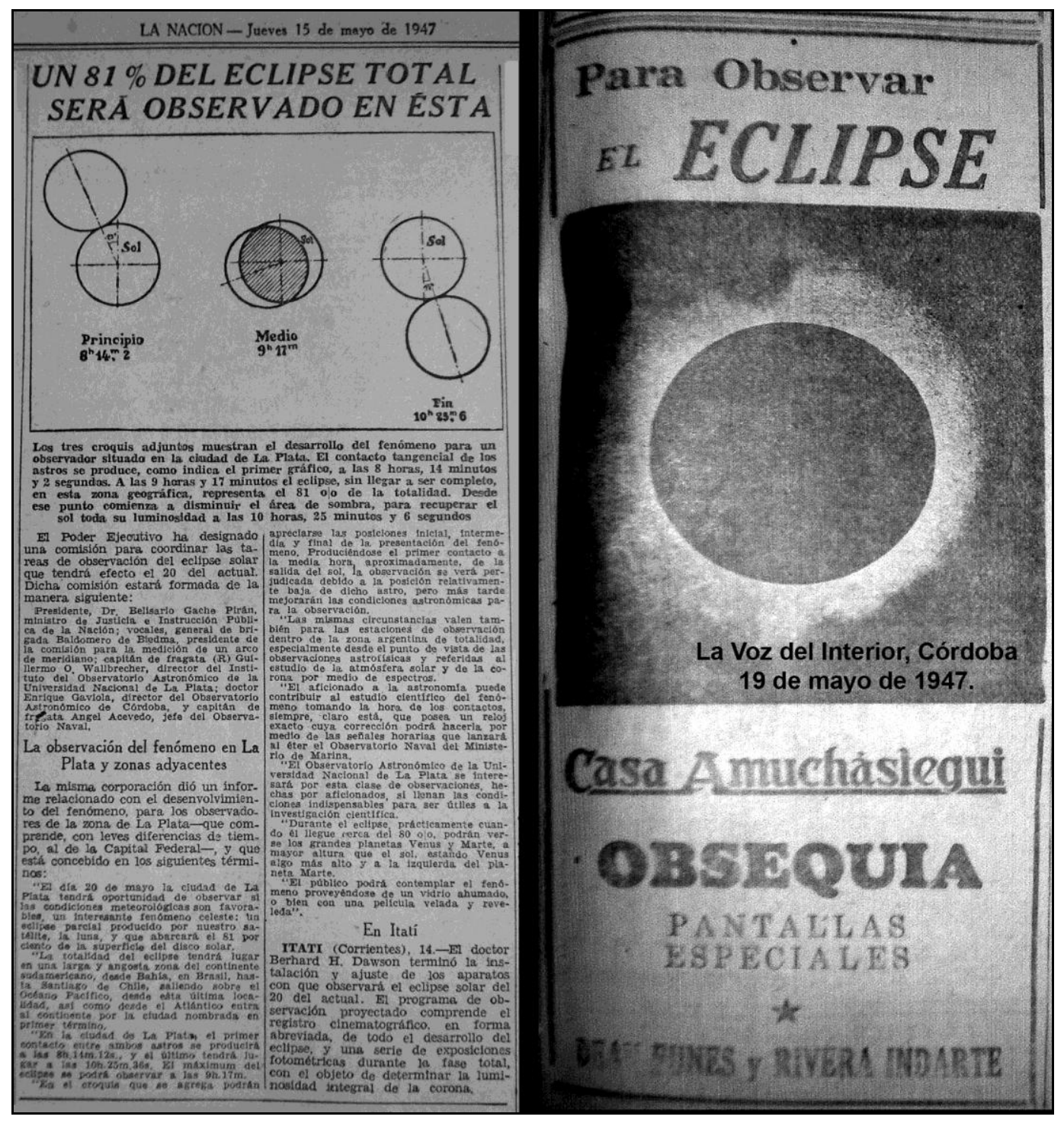

Figura 4 - Nota en el diario La Nación, de Capital Federal, y aviso publicitario en el diario La Voz del Interior, de Córdoba, sobre el eclipse de 1947.

Fuente: Hemeroteca Legislatura de la Provincia de Córdoba.

\section{Eclipses de Sol visibles desde Argentina en el período 1921-1960}

En el período que va desde 1921 a 1960 (40 años) fueron visibles desde el territorio argentino veinticinco (25) eclipses de Sol (ver todos sus datos en el Anexo).

Si bien a los fines del presente trabajo hemos tomado en cuenta a todos estos eclipses de Sol, por razones de completitud principalmente, hubieron varios en los cuales la zona de visibilidad fue mínima en lo geográfico (muy cerca de las fronteras, por ejemplo) o bien fueron visibles por un muy pequeño intervalo de tiempo (con el inicio o el final de eclipse muy próximo a la puesta o a la salida del Sol, respectivamente).

Estas condiciones hacen que en general tales eclipses sean, aún hoy, muy difíciles de ver en condiciones normales (no las propias de una expedición 
astronómica); el 15\% del total relevado corresponde a este tipo de eclipses "difícil" de observar, más aun pensando en que los protagonistas eran chicos, en la época bajo estudio, observadores casuales en principio y no intencionales "cazadores de eclipses". Este porcentaje de eclipses difíciles de visualizar, hace que el rango de eventos (eclipses de Sol) asociados a los recuerdos relevados sea bastante acotado, tanto en lo espacial como en lo temporal.

De los veinticinco eclipses antes citados, dieciocho (18) de ellos fueron visibles como "parcial", ya sea porque el eclipse en sí mismo lo era, o bien porque siendo anular o total las respectivas bandas de anularidad o totalidad no tocaban nuestro territorio. Tres (3) de estos eclipses están en la categoría "difícil".

Sólo cuatro (4) eclipses anulares y tres (3) eclipses totales (uno de estos en la categoría "difícil") pudieron verse desde Argentina en ese período. Cabe recordar que fuera de la muy estrecha zona de anularidad o de totalidad, el eclipse se ve como parcial, por lo que entonces la posibilidad de haber visto, como observador casual, en ese período un eclipse de Sol como parcial es mucho mayor que la de haber visto un eclipse anular o total (Tabla 1).

\begin{tabular}{|c|c|}
\hline $\begin{array}{c}\text { TOTAL DE ECLIPSES DE SOL VISIBLES DESDE ARGENTINA } \\
\text { EN EL PERÍODO 1921-1960 }\end{array}$ & $\mathbf{2 5}$ \\
\hline $\begin{array}{c}\text { Eclipses de Sol visibles únicamente como “parcial”. } \\
\text { 01/10/1921, 28/03/1922, 19/05/1928, 11/10/1931, 25/12/1935, 13/12/1936 } \\
\text { (“difícil”), 08/06/1937 (“difícil"), 29/05/1938, 12/10/1939, 01/10/1940, } \\
27 / 03 / 1941,25 / 01 / 1944,03 / 01 / 1946,30 / 05 / 1946 \text { (“difícil”), 12/11/1947, } \\
18 / 03 / 1950,07 / 03 / 1951,09 / 08 / 1953 .\end{array}$ & $\mathbf{1 8}$ \\
\hline $\begin{array}{c}\text { Eclipses de Sol anulares } \\
\text { (visibles como parcial fuera de la zona de anularidad). } \\
17 / 03 / 1923,03 / 01 / 1927,24 / 02 / 1933,20 / 08 / 1952\end{array}$ & $\mathbf{4}$ \\
\hline $\begin{array}{c}\text { Eclipses de Sol totales } \\
\text { (visibles como parcial fuera de la zona de totalidad). }\end{array}$ & $\mathbf{3}$ \\
\hline $21 / 10 / 1930$ (“difícil"), 20/05/1947, 12/10/1958 & \\
\hline
\end{tabular}

Tabla 1 - Eclipses de Sol visibles desde Argentina en el período 1921-1960.

Corresponde explicitar, además, que para este estudio sólo se han tomado en cuenta los eclipses de Sol visibles desde Argentina continental y Tierra del Fuego, no se tomaron en cuenta a Malvinas e Islas del Atlántico Sur ni al Sector Argentino del Continente Antártico. 


\section{La forma de relevar los recuerdos de los más viejos}

La forma de contactar a los adultos mayores fue totalmente informal, ya sea por ser parientes y conocidos nuestros o de amigos y colegas, o bien eran miembros de la comunidad donde vivimos, en algunos casos habiendo sido invitados a participar a través de otros adultos mayores que ya habían formado parte del estudio. Es decir, no hubo ningún factor de selección específico: por edad, origen, género, u otros.

En todos los casos, les presentábamos el trabajo que estábamos realizando sin dar información específica, y ellos aceptaban voluntariamente participar en el mismo. No había preparación ni anuncio previo de ningún tipo, y las entrevistas eran individuales, por más que en algún caso hubieron varios adultos mayores juntos.

El instrumento que hemos utilizado para relevar los recuerdos de los adultos mayores entrevistados ha sido un muy sencillo cuestionario (Tabla 2), el cual fue implementado de diversas maneras.

En su gran mayoría, comenzábamos charlando con los adultos mayores personalmente, en algunos casos ellos mismos escribían las respuestas y en otros lo hacíamos nosotros. Algunas entrevistas fueron audiograbadas, principalmente por la imposibilidad de escribir o a veces porque no era del agrado del entrevistado hacerlo, y luego entonces se transcribían a papel. La duración de las entrevistas fue en general de unos quince minutos. En unos pocos casos, los participantes respondieron a las preguntas del cuestionario a través del correo electrónico (por ejemplo, por vivir lejos de nuestra ubicación).

Las respuestas y descripciones casi siempre son breves, en general sin abundancia de detalles, y fueron muy pocos los adultos mayores que hicieron dibujos o esquemas sobre lo que recordaban.

\begin{tabular}{|l|l|}
\hline \multicolumn{2}{|c|}{ ECLIPSES DE SOL DE CUANDO ÉRAMOS CHICOS } \\
\hline Nombre y Apellido: & Fecha de nacimiento: \\
\hline $\begin{array}{l}\text { Haciendo un esfuerzo de memoria, tratá de recordar todos aquellos ECLIPSES DE SOL que } \\
\text { hayas visto en tu vida, especialmente aquellos de cuando eras chico. Escribí los datos que te } \\
\text { pedimos aquí, así como cualquier otra información o comentario que consideres importantes. }\end{array}$ \\
\hline - Fecha aproximada en que recordás haber visto el eclipse de Sol. \\
- Edad aproximada que tenías cuando viste este eclipse de Sol. \\
- Región, provincia, ciudad, etc., en donde estabas cuando viste el eclipse de Sol. \\
- Personas con quienes compartiste la observación del eclipse. \\
- Descrién te avisó del eclipse o cómo fue que te enteraste de que iba a ocurrir. \\
- sentiste, si pensaste algo particular, etc.). \\
\hline
\end{tabular}

Tabla 2 - Cuestionario implementado con los adultos mayores. 


\section{Análisis de los datos obtenidos}

Se describen a continuación los registros más representativos del estudio realizado, indicándose los datos de los adultos mayores entrevistados, los detalles de sus recuerdos, y nuestra elección de cuál habría sido el eclipse visualizado por cada persona, con algunos detalles extraídos de los mapas de eclipses brindados por la NASA (se indica en cada caso el porcentaje aproximado de cobertura de la superficie del disco solar por la Luna en el máximo del eclipse en cada lugar de observación, "obscuration" en inglés, valor diferente teóricamente y levemente menor que la "magnitud", pero más representativo de lo que se visualiza para quienes no son especialistas).

\section{$>\quad$ Manuela, 97 años (a fines de 2016)}

Manuela nació y vivió toda su vida en Facundo, Chubut. Recuerda haber visto un eclipse de Sol cuando tenía entre 10 años y 15 años, habiéndolo observado en compañía de chicos más grandes que ella. Recuerda que los ancianos decían mientras miraban que no había que reírse del Sol, que se podían quemar si se reían del Sol.

Nacida en 1919, el rango de eclipses posibles según el recuerdo de Manuela sería entre los años 1929 a 1934. En el período cercano a ese intervalo del recuerdo fueron visibles desde Facundo tres eclipses: el anular del 3 de enero de 1927 (Manuela habría tenido 8 años), el parcial del 11 de octubre de 1931 (12 años) y el anular del 25 de diciembre de 1935 (16 años).

Confiando en la memoria y en el recuerdo de Manuela, el eclipse en cuestión debería haber sido el del 11 de octubre de 1931, con una edad acorde a lo expresado por ella durante la entrevista. El eclipse habría sido visto como parcial, a media mañana, con aproximadamente un $56 \%$ del disco solar cubierto por la Luna durante el máximo.

\section{$>\quad$ Mariquita, 79 años (a fines de 2016)}

Cuando tenía 12 o 13 años, en la ciudad de Mercedes, provincia de Buenos Aires, Mariquita recuerda haber visto un eclipse parcial junto con su mamá, quien estaba enterada de la ocurrencia de este fenómeno, utilizando una placa fotográfica.

Nacida en 1937, el eclipse en cuestión debiera haber ocurrido cerca de 1949/1950. En aquella época, el único eclipse fue el anular del 20 de agosto de 1952, visible como parcial desde Mercedes, con un 75\% del disco solar cubierto; Mariquita habría tenido 15 años, aproximadamente.

\section{$>\quad$ Enrique, 82 años (a fines de 2016)}

Enrique recuerda haber visto un eclipse cuando tenía unos diez años, desde Río Senguerr. Se enteró por la radio que se escuchaba en el lugar, y todos salieron a mirarlo.

Nacido en 1934, Enrique habría tenido 10 años en 1944. Los eclipses visibles desde Río Senguerr en esa época fueron: el total del 29 de mayo de 1938, visible como parcial (con sólo 4 años de edad), el anular del 27 de marzo de 1941, visible como parcial. Sol (con 7 años de edad), y el total del 20 de mayo de 1947, también visible como parcial (con 13 años de edad). Es posible que, por rangos de edad y por sus comentarios, el eclipse que recuerda Enrique pudiera ser el del 20 de mayo de 1947, visible a media mañana con un $62 \%$ del disco solar cubierto, aproximadamente. 


\section{$>\quad$ Inés, 78 años (a fines de 2017)}

Entre 1947 y 1950, Inés recuerda que cuando tenía entre 8 y 11 años, vio un eclipse de Sol, a eso del mediodía, desde la Villa del Lago Futaláufquen, en Chubut. Sus hermanas ahumaban vidrios para mirarlo, y fue su padre quien les avisó del eclipse.

Nacida en 1939, es muy posible que el eclipse que observó Inés fuera el total del 20 de mayo de 1947, con una cobertura de poco más del 60\%; Inés habría tenido 8 años.

\section{Alicia R., 65 años (a mediados de 2006)}

Alicia recuerda que, junto con su hermana y sus padres, observó un eclipse de Sol, desde Comodoro Rivadavia, provincia del Chubut, en el verano de 1951. Su papá fue quien sabía del eclipse. Ella tenía unos 10 años, y lo vio protegiéndose los ojos con un negativo. Le gustó y fue divertido.

Nacida en 1941, en la época de su recuerdo ocurrieron sólo dos eclipses, visibles ambos como parcial desde Comodoro Rivadavia: el anular del 20 de agosto de 1952, a mediodía, con un 51\% de cobertura, aproximadamente (Alicia habría tenido 11 años) y el parcial del 9 de agosto de 1953, con muy poca cobertura, $1 \%$, por estar casi en el límite de la zona de visibilidad (con 12 años de edad).

Es de suponer entonces que el eclipse que recuerda Alicia haber observado podría ser el del 20 de agosto de 1952, aunque no habría sido en verano sino aún en el invierno patagónico.

\section{$>\quad$ Magdalena, 93 años (a principios de 2016)}

Cuando tenía 24 años, en 1947, Magdalena trabajaba en una oficina administrativa en Lomas de Zamora, provincia de Buenos Aires, y al mediodía se produjo un eclipse de Sol que ella y sus compañeros observaron sin protección alguna. Tiempo después, como veía las letras corridas, difusas o dobles, la enviaron a ver un oftalmólogo que le dio licencia médica por una semana.

El eclipse en cuestión fue el total del 20 de mayo de 1947, observable desde el Gran Buenos Aires como parcial, con un $75 \%$ de cobertura del disco solar, aproximadamente.

\section{$>$ José Luis, 93 años (a principios de 2016)}

En los últimos años de la década de 1930, José Luis recuerda que vio un eclipse de Sol acompañado por dos tías, quienes habían ahumado un vidrio a través del cual lo observaron, desde el centro de la ciudad de La Plata, en la provincia de Buenos Aires. Supone que se enteraron porque en su casa recibían diariamente el diario local, El Día.

En esa época se observaron desde La Plata, como parcial, los siguientes eclipses: el total del 29 de mayo de 1938, el total del 1 de octubre de 1940 y el anular del 27 de marzo de 1941. Dado que los recuerdos de José Luis no aportan mayores detalles, no es posible discriminar cuál de los tres eclipses visibles desde su lugar de observación podría haber visto cuando niño. 


\section{$>$ Esteban, 78 años (a fines de 2016)}

Hacia el año 1945, con 7/8 años de edad, Esteban recuerda haber visto con su familia un eclipse de Sol desde San Salvador de Jujuy, habiéndose enterado del mismo en la escuela.

Recuerda observar cuando la Luna comenzaba a ponerse delante del Sol, formando un anillo que luego fue cubriendo. Los mayores les decían que no miraran en forma directa al Sol y que utilizaran un vidrio oscuro o una placa radiográfica, lo que les permitía observar el fenómeno. Estima el tiempo de observación en aproximadamente media hora o un poco más.

Nacido en 1938, su recuerdo remite a los años 1945/1946. En aquella época ocurrieron tres eclipses: el total del 25 de enero de 1944 (5/6 años de edad), el total del 20 de mayo de 1947 y el anular del 12 de noviembre de 1947 (ambos con 8/9 años de edad). Por el recuerdo de Esteban, pareciera posible que el eclipse en cuestión pudiera ser el total del 20 de mayo de 1947, ya que la banda de totalidad estuvo relativamente cerca de San Salvador de Jujuy, con casi un 94\% de cobertura del disco solar.

\section{$>$ Gladis, 85 años (a mediados de 2016)}

Hacia 1944, cuando tenía 12 años, Gladis recuerda haber visto un eclipse acompañada por su abuelo, sus hermanos y sus primos, desde Adrogué, en la provincia de Buenos Aires. Quien les avisó de la ocurrencia del fenómeno fue su abuelo. Todos utilizaron anteojos especiales para evitar que les hiciera mal verlo, supone que quizás estaban hechos con radiografías viejas. Fue todo un acontecimiento muy grande, sentir una sensación de maravilla.

Nacida en 1931, con 12 años Gladis debió haber visto el eclipse total del 25 de enero de 1944, el cual se vio como parcial desde la provincia de Buenos Aires, con aproximadamente un $10 \%$ de cobertura.

\section{$>\quad$ Ilda, 65 años (a mediados de 2008)}

En Esquel, desde el patio de su casa, con un hermano mayor, vio un eclipse de Sol que no recuerda muy bien; estima que tendría unos 10 años de edad.

Lo recuerda como algo curioso, porque los padres "no nos daban permiso" para observarlo porque podía verse afectada la vista: "se van a estropear los ojos". No los dejaban mirar con ninguna protección siquiera, pero recuerda que con su hermano tenían unos negativos de fotos y con eso lo miraron, cuando su mamá se fue a la cocina, escondidos en el patio en un tronco de un viejo árbol. Fue un hermoso recuerdo, con su hermano, algo compartido, algo prohibido, les gustó jugar y disfrutar con ello.

Por la época, Ilda seguramente debe haber observado el eclipse del 20 de agosto de 1952, visible como parcial desde Esquel, con una cobertura del 51\%, con una edad de 8/9 años.

\section{$>\quad$ Margarita, 88 años (a fines de 2016)}

Margarita recuerda que tenía 23 años, aproximadamente, cuando vio un eclipse junto con su esposo y sus tres hijos, en la zona de campo en la provincia del Chaco. Su recuerdo es muy vívido, con gran cantidad de detalles. Recuerda que se rumoreaba que 
algo iba a pasar, pero nadie le dio importancia, hasta que sucedió mientras trabajaban, y nadie sabía que era un eclipse. Se encontraban en ese momento muchas familias juntas trabajando en el campo, y de repente el día claro empezó a ponerse de un color gris hasta llegar a una oscuridad completa. Todos dejaron de trabajar por miedo a que pasara algo. Recuerda que las gallinas se fueron al gallinero a dormir, y que ella buscó a sus hijos y se agruparon junto a su marido por temor.

Lo que recuerda Margarita claramente remite a lo que se percibe durante un eclipse total de Sol. Nacida en 1928, con aproximadamente 23 años el eclipse habría sucedido en 1951. En esa época, el único eclipse total de Sol, con la banda de totalidad pasando por el Chaco, fue el que ocurrió el 20 de mayo de 1947: su edad habría sido entonces de 19 años (Figura 5).

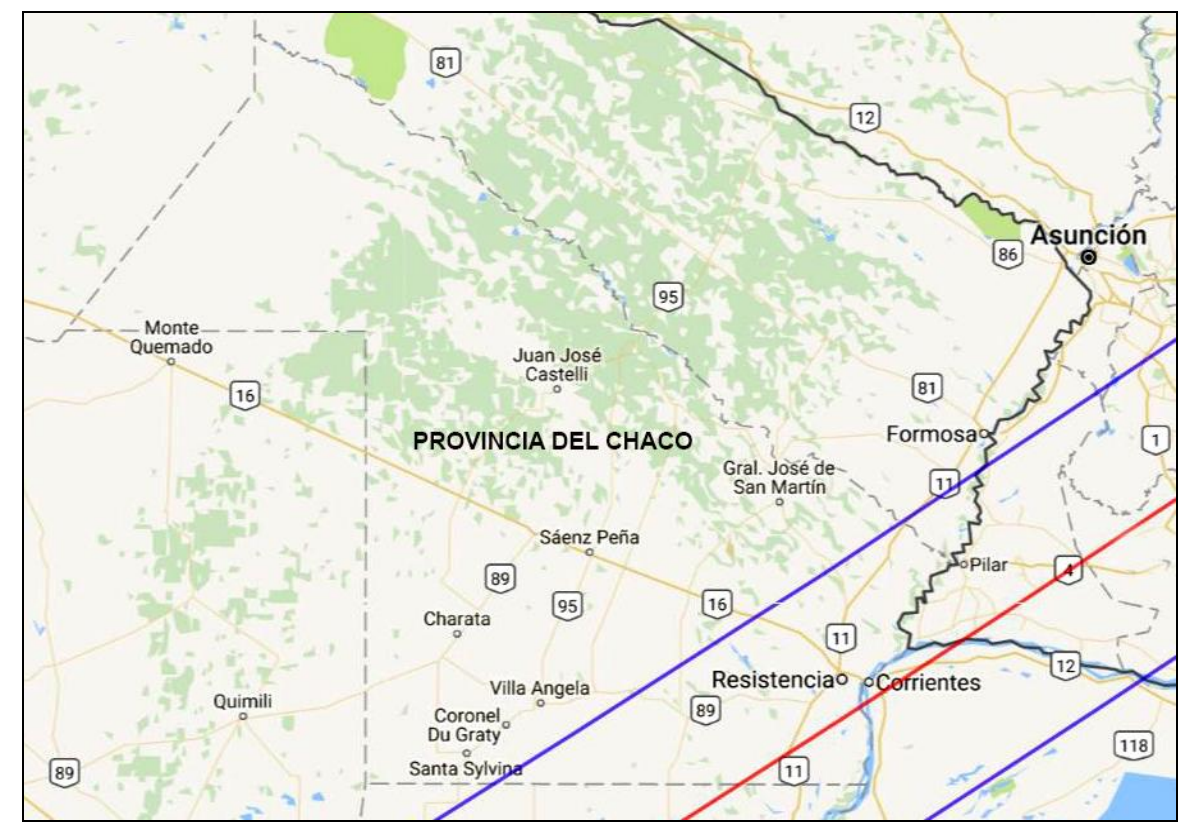

Figura 5 - Captura de pantalla del mapa de visibilidad del eclipse total de Sol del 20 de mayo de 1947.

Fuente: NASA (2017).

\section{Olga, 77 años (a mediados de 2006)}

En 1953, con 21 años, Olga recuerda haber visto un eclipse solar desde su casa en Esquel, del cual se enteró la semana anterior por su esposo. Cuando llegó el día del eclipse, su esposo le trajo una antiparra, con vidrios de color azul, ya que no quiso que lo viese sin los anteojos porque se decía que la penetración (sic) solar quemaba la vista.

Nacida en 1929, Olga tenía 23 años cuando observó, es muy posible, el eclipse anular del 20 de agosto de 1952, visto como parcial desde Esquel, con el $51 \%$ de cobertura, ya que el anterior fue cuando tenía 17 años, el 20 de mayo de 1947, y el posterior fue en 1953. 


\section{$>\quad$ Jorge, 83 años (a principios de 2016)}

Hacia 1944, desde San Rafael, en la provincia de Mendoza, Jorge recuerda que con 8 años, o quizás 10 años, observó con su abuelo un eclipse de Sol, del cual se enteró por la escuela.

En aquella época fueron visibles desde Mendoza dos eclipses: el total del 27 de marzo de 1941 (con 8 años de edad), el total del 25 de enero de 1944 (con 11 años de edad), ambos como parcial.

Confiando en el recuerdo de Jorge, y dado que en enero no se asiste a la escuela, es posible que el eclipse que observó junto a su abuelo haya sido el del 27 de marzo de 1941, con una cobertura del 39\%, aproximadamente.

\section{$>$ Héctor, 78 años (a principios de 2016)}

Hacia 1950, con 12 años, Héctor recuerda haber visto un eclipse junto con sus compañeros de colegio en Buenos Aires. Los docentes del colegio fueron quienes organizaron la observación, entregándoles trozos de radiografías a efecto de no afectar la vista. "De repente sentimos un intenso deseo de saber qué significado debíamos esperar, la vista resulta única, un raro misterio al que asomamos a través de un vidrio ahumado".

En aquella época, fueron visibles desde Buenos Aires dos eclipses, ambos como parcial: el total del 20 de mayo de 1947, con un 75\% de cobertura (con 9 años de edad) y el anular del 20 de agosto de 1952, con un 87\% de cobertura (con 14 años de edad). Confiando en el recuerdo de Héctor, en el dibujo que realizó (Figura 6) y en el porcentaje de cobertura de los dos eclipses antes indicados, se podría suponer que el eclipse observado fue el del 20 de agosto de 1952, con 14 años pero aún en la escuela Primaria.

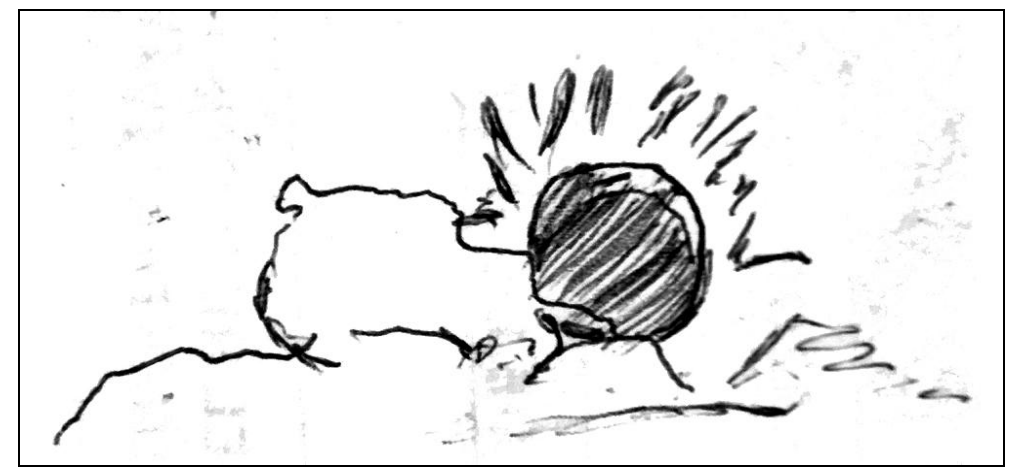

Figura 6 - Dibujo de Héctor, sobre el eclipse de Sol que recuerda haber visto en el colegio.

\section{$>$ Carlos, 72 años (a principios de 2016)}

Nacido en 1944, Carlos recuerda que en la década del 1950 vio un eclipse desde el sur del Gran Buenos Aires, junto con sus padres y sus abuelos, quienes se enteraron por la radio.

El 20 de agosto de 1952 se vio desde la zona donde vivía Carlos, de 8 años, un eclipse anular (visible como parcial), con un $87 \%$ de cobertura aproximadamente, después del mediodía (Figura 7). 


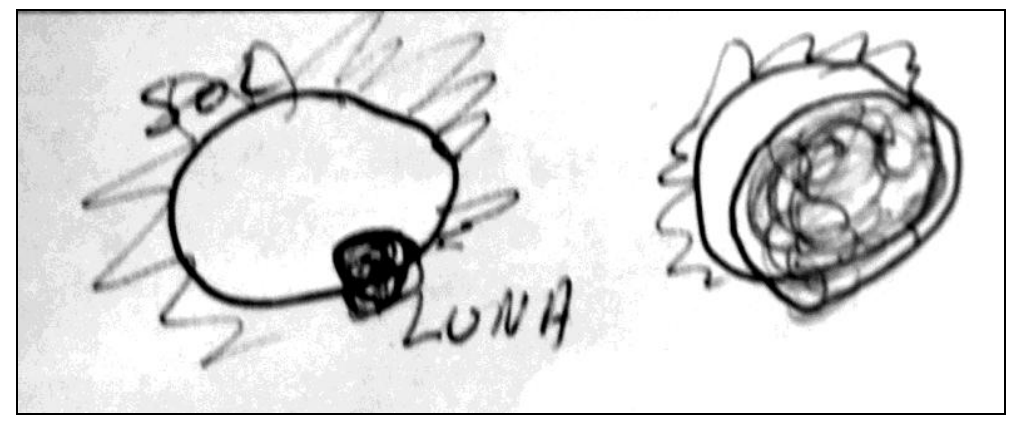

Figura 7 - Dibujo de Carlos, sobre el eclipse de Sol que recuerda haber visto con sus padres y abuelos.

\section{$>$ Gladis, 72 años (a fines de 2006)}

Hacia 1953, Gladis recuerda que con 9 años observó con sus compañeros del barrio, en Esquel, provincia del Chubut, un eclipse de Sol, del cual se enteraron por sus maestros en la Escuela $\mathrm{N}^{\circ} 54$.

"Nos movilizamos mucho tratando de conseguir negativos de fotos. No había casi comercios de fotos. El maestro nos aconsejaba. La familia no acompañaba mucho. Mirar el cielo era raro, no ocupaba mucho lugar en las actividades familiares".

Nacida en 1944, Gladis tenía 8 años cuando ocurrió el eclipse anular del 20 de agosto de 1952, y 9 años cuando ocurrió el eclipse parcial del 9 de agosto de 1953, ambos vistos como parcial desde Esquel. Es de suponer que el eclipse que vio Gladis fue el del 20 de agosto de 1952, por su duración y cobertura (51\%).

\section{Alicia T., 65 años (a fines de 2008)}

Entre 1952 y 1954, Alicia recuerda que con 9/11 años observó un eclipse de Sol desde Capital Federal. Lo comentaban los adultos, y sus primos algo mayores que ella se preparaban con entusiasmo para verlo a través de un vidrio de botella oscuro. Sin embargo, los adultos advertían que no se mirara por el riesgo de quedar ciegos.

En aquella época, desde la ciudad de Buenos Aires fue visible, como parcial, únicamente el eclipse anular del 20 de agosto de 1952, con una cobertura del 87\% aproximadamente, a mediodía. Alicia habría tenido aún 11 años.

\section{$>$ Leonor, 70 años (a fines de 2008)}

Con 15 años, hacia 1953, Leonor recuerda que junto con sus compañeros de colegio vio un eclipse en Coronel Suárez, provincia de Buenos Aires, de lo cual se enteró por sus profesores. Si bien no recuerda qué vio, sí tiene presente que la recomendación era no verlo directamente sino a través de vidrios ahumados o radiografías.

Nacida en 1938, es posible también que Leonor haya visto el eclipse del 20 de agosto de 1952, con un $75 \%$ de cobertura, el cual fue visible como parcial en casi toda la Argentina, exceptuando el extremo norte por donde cruzaba la banda de anularidad. 


\section{$>$ Elena, 83 años (a principios de 2017)}

Hacia 1945/1946, con 10/11 años, Elena recuerda que estando en Cholila, provincia del Chubut, vio un eclipse de Sol junto con su padre y su hermana. Los mayores no las dejaban mirar al Sol sin proteger los ojos con un vidrio oscuro. Supone que se enteraron por la radio o por el diario La Prensa (sic).

En esa época, desde Cholila se pudieron observar el eclipse parcial del 30 de mayo de 1946 (uno de los "difícil" de observar, visible al inicio pero en la puesta) y el eclipse total del 20 de mayo de 1947, visible como parcial con un 62\% de cobertura. En este último, quizás más probable de ser observado desde esta región, Elena habría tenido $13 / 14$ años.

\section{$>\quad$ Raine, 65 años (a fines de 2008)}

Cuando tenía entre 6 y 10 años de edad, hacia los años 1950 a 1956, Raine recuerda haber visto un eclipse junto a su hermana y a sus padres, desde Mar del Plata, en la provincia de Buenos Aires. Su padre los preparó para ver algo, y a ella le interesó mucho ver cómo preparaba trozos de vidrio que luego tiznó, a través de los cuales luego tenían que mirar. Era una jornada luminosa, y su padre montó una suerte de ceremonia para la observación.

Con casi 8 años de edad, Raine observó seguramente el eclipse anular del 20 de agosto de 1952, visible como parcial desde Mar del Plata, con un 75\% de cobertura.

\section{$>\quad$ Josefa, 74 años (a fines de 2006)}

Josefa recuerda que en la década de 1940, tenía entre 10 y 14 años, observó un eclipse solar desde Bernal, en la provincia de Buenos Aires. Recuerda que el barrio estaba alborotado por el evento, y que ella lo observó junto con una amiga de su edad y la hermana de su amiga mucho mayor que ellas. Recuerda la histeria (sic) de quienes les advertían no mirarlo sin protección. Los mayores ahumaban vidrios, ellas los usaban pero también espiaban apenas y luego se quedaron preocupadas porque veían destellos en su vista. Fue por la mañana. También recuerda las burlas que la hermana mayor de su amiga les hacía por la ignorancia que ambas tenían acerca del eclipse.

En aquella época, ocurrieron tres eclipses visibles como parcial desde Bernal: el anular del 27 de marzo de 1941 (39\% de cobertura, aproximadamente), el total del 25 de enero de 1944 (10\% de cobertura, aproximadamente) y el total del 20 de mayo de 1947 (75\% de cobertura, aproximadamente). Los detalles del recuerdo de Josefa no permiten discriminar cuál de estos eclipses observó.

\section{$>\quad$ Violeta, 87 años (a principios de 2017)}

Estando en Rivadavia, provincia de Mendoza, recuerda que se vio el Sol mucho más grande que lo habitual, y empezó a "desplazarse despacito". Dice que tenía unos 7/8 años, que lo vio con su papá, y supone que fue a mediodía porque era bien de día.

Por su ubicación (Figura 8) y por su relato (¿Violeta habrá visto la corona solar?), pareciera que su recuerdo remite al eclipse total del 20 de mayo de 1947, visto dentro de la banda de totalidad. Sin embargo, no coincide por mucho la edad que ella 
supone que tenía al verlo, ya que nacida en 1929, Violeta habría tenido 17/18 años cuando sucedió este eclipse total.

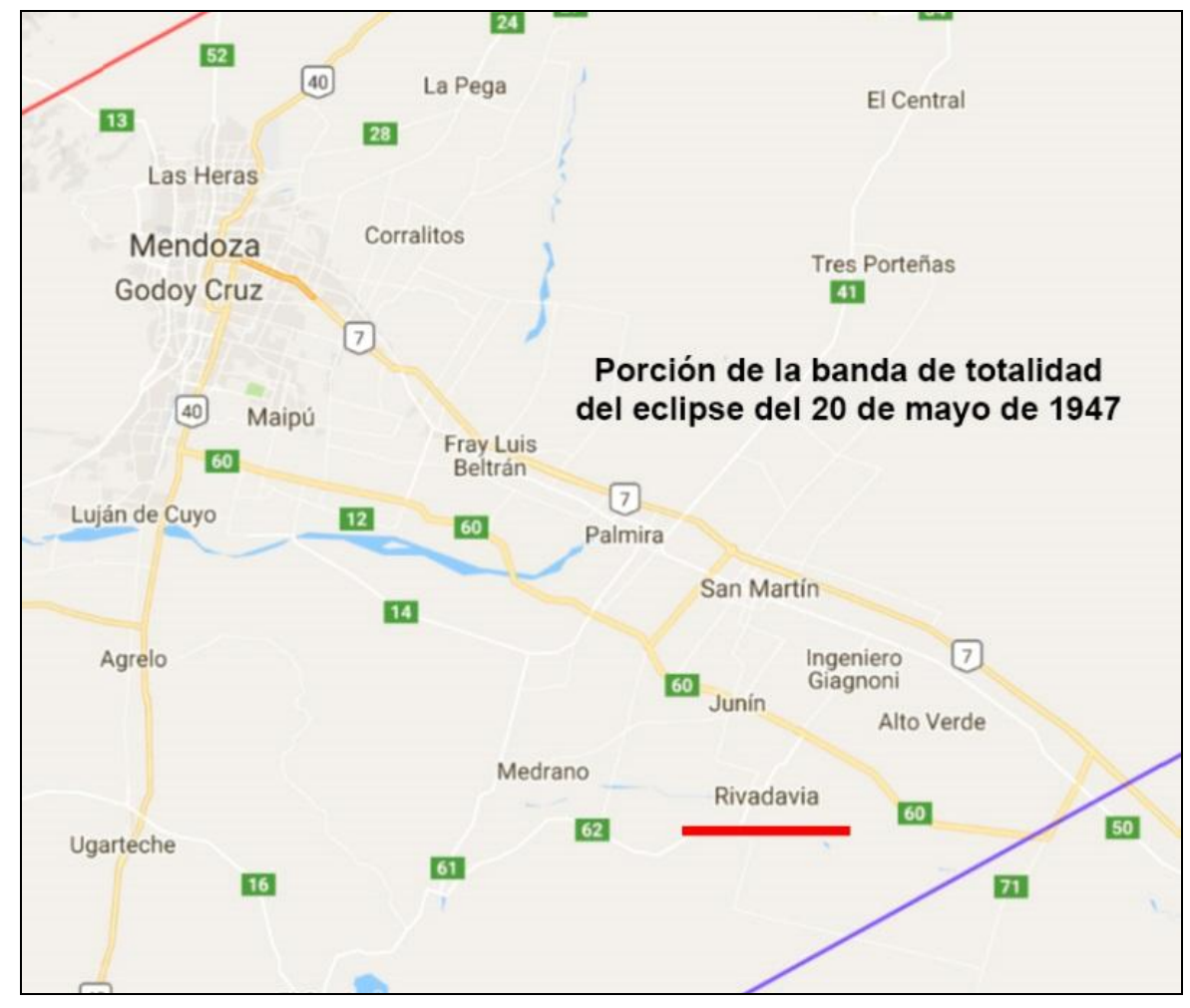

Figura 8 - Captura de pantalla del mapa de visibilidad del eclipse total de Sol del 20 de mayo de 1947.

Fuente: NASA (2017).

\section{$>\quad$ Emilio, 81 años (a fines de 2006)}

Emilio nació en 1925, y recuerda que con unos 10/11 años vio un eclipse junto con sus padres, hermanos y primos, desde la zona rural entre Quilmes y La Plata, en la provincia de Buenos Aires, hacia los años 1948/1949. Recuerda que tiene la imagen de oír "chillar" a los gorriones al llegar la totalidad y que habían venido a estacionarse en los árboles de alrededor como lo hacían todos los días al anochecer, y que le quedó como un "juego" que el Sol le hizo a los gorriones.

En la época referida por Emilio no ocurrió ningún eclipse total visible desde la provincia de Buenos Aires. El eclipse total del 20 de mayo de 1947 se vio desde esa zona con una cobertura del $80 \%$ aproximadamente, y el eclipse anular del 20 de agosto de 1952 se vio desde esa zona con una cobertura del 90\% aproximadamente, pero en ninguno de los dos casos habrían ocurrido efectos en el entorno natural tales como los recordados por Emilio.

\section{Otros recuerdos e imágenes asociados a eclipses de Sol}

Muchos otros adultos mayores entrevistados para el presente trabajo han expresado recuerdos asociados con los eclipses solares, pero sin detalles descriptivos como en los anteriores casos ni tampoco con claras referencias en cuanto a la ubicación 
espacio-temporal necesarias para definir un eclipse en particular. Sin embargo, estos recuerdos nos muestran interesantes aspectos de la construcción social existente en nuestra sociedad relacionados con los eclipses de Sol (cuidados, miedos, etc.).

Margarita (68 años a fines de 2008) recuerda que cuando estaba en los primeros grados de su escuela primaria $\mathrm{N}^{\circ} 57$ en Trevelin, provincia del Chubut, hubo un eclipse que ella no vio, pero su maestro, oriundo de Luján en la provincia de Buenos Aires, les contó que cuando él era chico vio un eclipse y mucha gente también lo vio sin protección, y se lastimaron la vista, por lo que les insistía en utilizar la protección adecuada, y no utilizar vidrios de colores, o vidrios ahumados con velas, o rollos velados, porque eran muy peligrosos.

Margarita (67 años a mediados de 2007) recuerda que estando embarazada de cuatro meses ocurrió un eclipse de Sol, pero que la dueña de la casa donde vivía con su esposo no le permitió verlo porque era nocivo para su salud considerando su estado.

Hipólito (90 años a fines de 2016) recuerda haber visto un eclipse a través de vidrios ahumados desde Córdoba, y que sintió temor al observarlo.

Vicente (67 años a mediados de 2016) recuerda haber visto a los 14 años desde Buenos Aires un eclipse a través de vidrios de soldador, junto con su madre y su hermano, y que sentía que el eclipse era un fenómeno normal de la naturaleza.

Lilia (63 años a principios de 2016) ver un eclipse desde Trevelin, que le dio mucho miedo, pero su abuelo le dijo que "son cosas que pasan".

Héctor (87 años a fines de 2016) recuerda haber visto un eclipse observando el agua de una fuente en la ciudad de Buenos Aires, en los años 70', y que otra forma de observarlo era a través de vidrios muy oscuros. Había mucha gente, circulando por el centro cerca de Diagonal Norte.

Silvia (65 años a principios de 2011) recuerda haber visto un eclipse estando en la secundaria, en Buenos Aires. Toda la escuela salió al patio a ver el eclipse, circulaba una alegría especial, con un poco de adrenalina y algo de miedo ("te podés quedar ciega", decían algunos). Pensó que eran unos privilegiados porque los dejaban salir a todos juntos para ver algo nuevo.

Luis (68 años a fines de 2016), recuerda que su papá médico llegó a casa con radiografías veladas para ver un eclipse cuando él era muy chico.

Lilia (83 años a principios de 2017), vivió en el campo sus primeros años de vida hasta la mitad de la primaria, y dice que no vio un eclipse en aquella época porque "nadie sabía lo que era eso" ya que no se tenía información.

Teresa (70 años a fines de 2016), recuerda que miraron un eclipse a través de un vidrio oscuro, y que se enteraron por haber escuchado la noticia por la radio.

Por otra parte, algunos adultos mayores que respondieron a nuestra propuesta, quienes viven en la Patagonia desde hace décadas, eran extranjeros, y sus recuerdos aportan detalles interesantes que vale la pena presentar, más allá de no remitir a eclipses de Argentina.

- Nelson (81 años a fines de 2016), recuerda haber visto un eclipse solar a través de vidrios ahumados con velas, cuando tenía unos 16 años, en la escuela secundaria desde La Serena en Chile. 
- Virginia, 91 años (a fines de 2016), vive en Facundo desde hace décadas, y recuerda que vio con su padre un eclipse desde Chiloé, en Chile, cerca del mediodía, cuando tenía entre 10 años y 13 años, "se veía luminoso, grande, como una Luna, y no duró mucho, la gente comentaba que era un eclipse solar pero que ya no se iba a repetir". A ella le dio impresión, tuvo miedo.

- Ana (77 años a fines de 2009), oriunda de España, dice que cuando estalló la Guerra seguramente la gente no tenía ganas de ver el Sol ni la Luna. Más tarde hubo un eclipse, pero la gente decía que "se quemaban los ojos", así que no salían a la calle. No había mucha información.

- Raquel (65 años a mediados de 2007) cuenta que cuando muy niña se vio un eclipse desde Santiago de Chile, pero a ella sus padres no la dejaron verlo por los riesgos para la vista. Ella se quedó muy intrigada, más porque sus mayores lo observaron utilizando vidrios ahumados. La gente decía que se te podía "secar la vista".

- Nacha (80 años a principios de 2007) recuerda que vio un eclipse en España, cuando tenía 13/14 años, después de la Guerra. Lo miraron con vidrios ensuciados con carbón, y lo observaron hasta que se terminó ya que tenían miedo de que si el Sol no regresaba comenzaría la guerra nuevamente.

\section{Un mismo eclipse, muchos chicos observándolo}

Es muy interesante notar que existen registros de diferentes personas, adultos mayores, quienes cuando chicos vivían en muy distintos lugares de nuestro país (y que obviamente no se conocían entre sí), que recuerdan haber visto un eclipse de Sol el cual, a partir del presente estudio, es posible afirmar que fue el mismo eclipse. Son dos eclipses los que hemos relevado que cumplen con esta característica: el total del 20 de mayo de 1947 y el anular del 20 de agosto de 1952.

\section{$>$ Eclipse total de Sol del 20 de mayo de 1947}

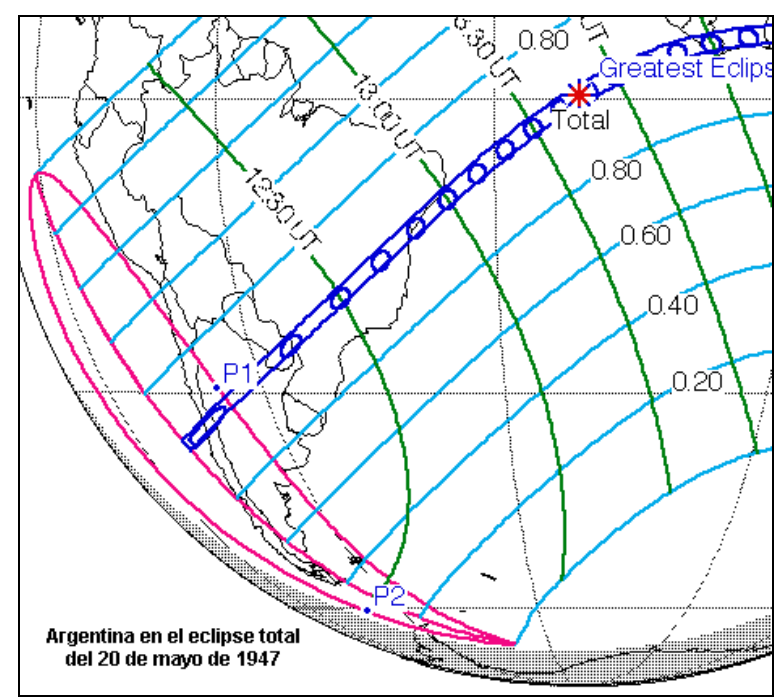

Figura 9 - El eclipse total de 1947 a través de Argentina.

Fuente: Captura de pantalla, luego editada, tomada de NASA (2017).

Las personas que según los recuerdos recogidos observaron este eclipse son las siguientes: 
- Enrique, 82 años (a fines de 2016), recuerda haberlo visto desde Río Senguerr (70\% de cobertura); habría tenido 13 años.

- Margarita, 88 años (a fines de 2016), recuerda haberlo visto desde el campo en el Chaco (dentro de la banda de totalidad); habría tenido 19 años.

- Esteban, 78 años (a fines de 2016), recuerda haberlo visto desde San Salvador de Jujuy (90\% de cobertura); habría tenido 8/9 años.

- Magdalena, 93 años (a principios de 2016), recuerda haberlo visto desde Lomas de Zamora (con un 80\% de cobertura); habría tenido 24 años.

- Elena, 83 años (a principios de 2017), recuerda haberlo visto desde Cholila (70\% de cobertura); habría tenido 13/14 años.

- Violeta, 87 años (a principios de 2017), recuerda haberlo visto desde Rivadavia (dentro de la banda de totalidad); habría tenido 17/18 años.

- Inés, 78 años (a principios de 2017), recuerda haberlo visto desde la Villa del Lago Futaláufquen; habría tenido 8 años.

Ubicados todos ellos en un mapa de Argentina junto con la banda de totalidad (Figura 10), se puede ver la dispersión de regiones desde las que fue visto este eclipse por aquellos chicos en los últimos años de la década del ' 40.

El eclipse de 1947 tuvo gran trascendencia en el entorno científico, realizándose diversas expediciones por equipos de astrónomos de los observatorios argentinos, tanto dentro de Argentina como a Brasil (PAOLANTONIO, 2011; ASOCIACIÓN ARGENTINA AMIGOS DE LA ASTRONOMÍA, 1947) (Figura 11).

Es de suponer que además de la importancia en el ámbito específicamente astronómico, este eclipse tuvo también un alto impacto en los medios de comunicación de la época, por lo que es posible suponer que en especial las escuelas de aquel entonces habrán difundido y convocado a los chicos y sus familias para que pudieran observar este fenómeno, como se desprende del análisis antes realizado sobre los datos obtenidos en el presente estudio.

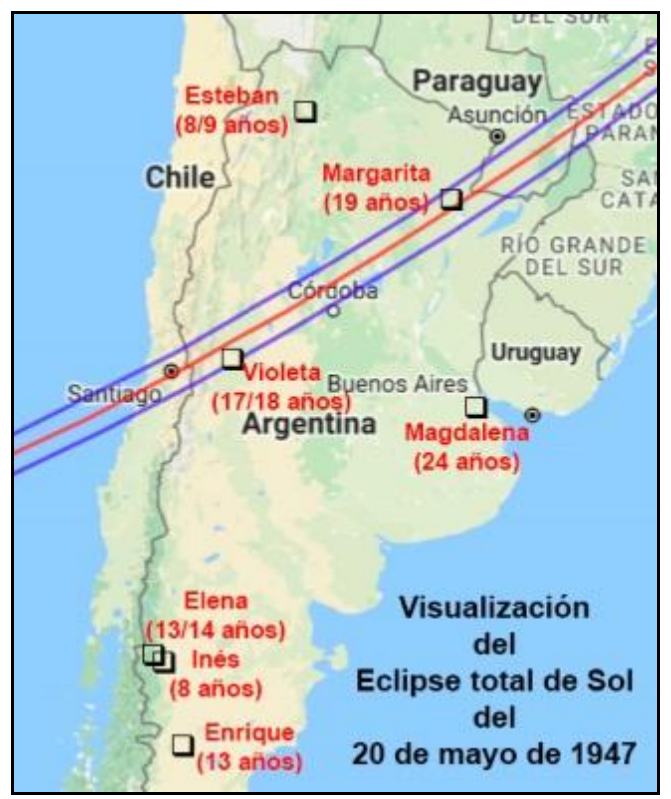

Figura 10 - El eclipse total de 1947 visto por muchos chicos de Argentina. Fuente: Captura de pantalla, luego editada, tomada de NASA (2017). 


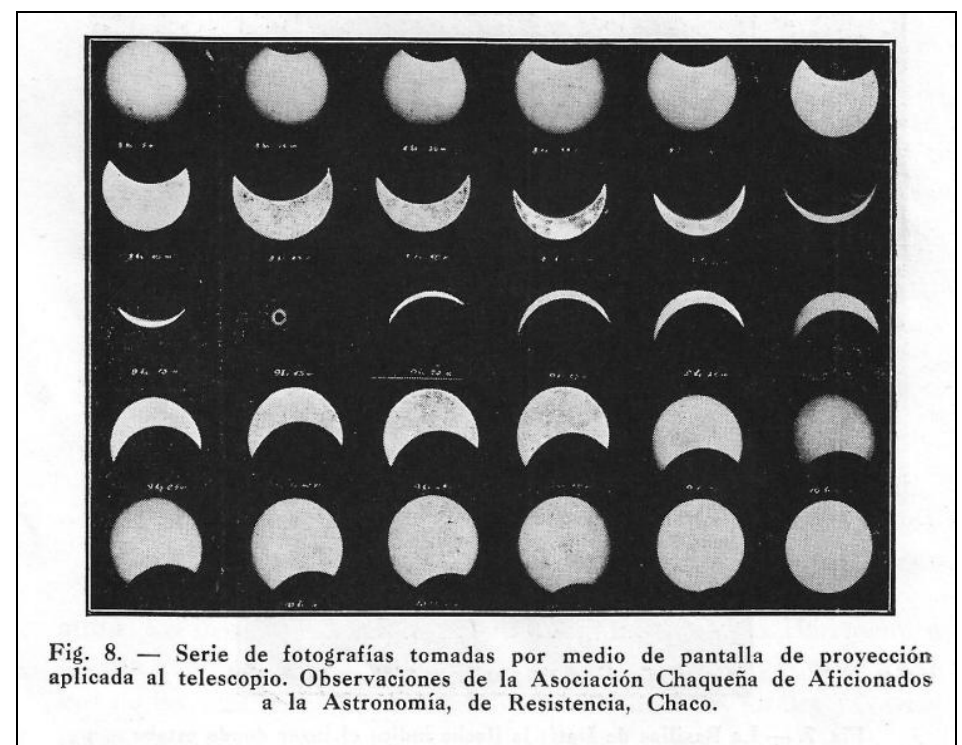

Figura 11 - Registro fotográfico del eclipse total del 20 de mayo de 1947, desde Resistencia, Chaco.

Fuente: Revista Astronómica, n.119, 1947.

\section{Eclipse anular de Sol del 20 de agosto de 1952.}

En la Figura 12 se muestran los mapas con la banda de anularidad que cruzó el norte de Argentina en agosto de 1952.

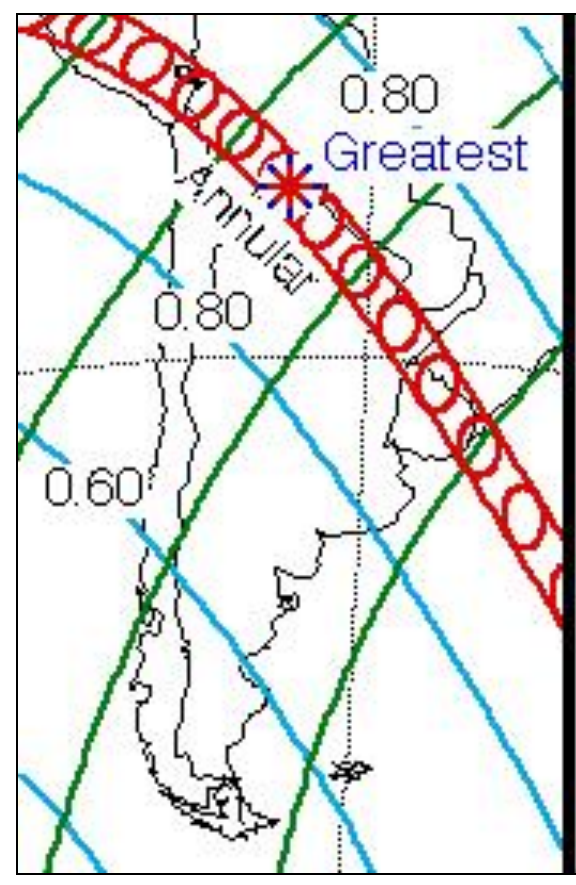

(A)

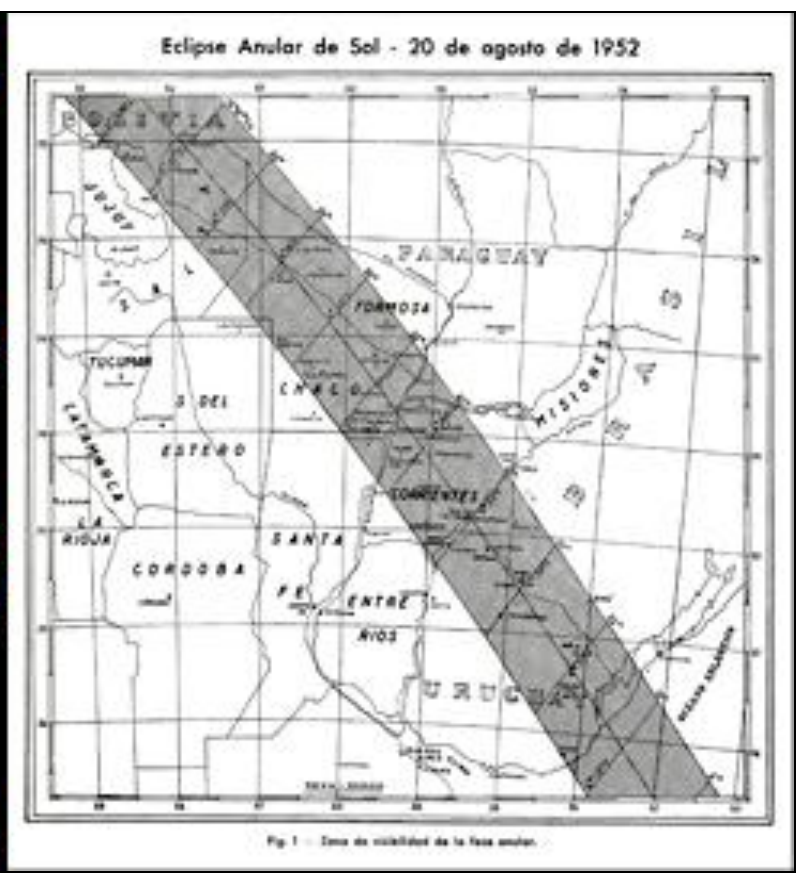

(B)

Figura 12 - (A) El eclipse anular de 1952 a través de Argentina.

(B) Zona de anularidad del eclipse del ' 52.

Fuente: (A) Captura de pantalla, luego editada, tomada de NASA (2017).

(B) Revista Astronómica, n.130, 1952. 
siguientes:

Las personas que según los recuerdos recogidos observaron este eclipse son las

- Mariquita, 79 años (a fines de 2016), recuerda haberlo visto desde Mercedes, provincia de Buenos Aires (80\% de cobertura); habría tenido 15 años.

- Alicia R., 65 años (a mediados de 2006), recuerda haberlo visto desde Comodoro Rivadavia (60\% de cobertura); habría tenido 11 años.

- Alicia T., 65 años (a fines de 2008), recuerda haberlo visto desde Capital Federal ( $90 \%$ de cobertura); habría tenido 11 años.

- Gladis, 72 años (a fines de 2006), recuerda haberlo visto desde Esquel (60\% de cobertura); habría tenido 8 años.

- Olga, 77 años (a mediados de 2006), recuerda haberlo visto desde Esquel (60\% de cobertura); habría tenido 17 años.

- Leonor, 70 años (a fines de 2008), recuerda haberlo visto desde Coronel Suárez (80\% de cobertura); habría tenido 14 años.

- Ilda, 65 años (a mediados de 2008), recuerda haberlo visto desde Esquel (60\% de cobertura); habría tenido 8/9 años.

- Raine, 65 años (a fines de 2008), recuerda haberlo visto desde Mar del Plata (80\% de cobertura); habría tenido 8 años.

- Héctor, 78 años (a principios de 2016), recuerda haberlo visto desde la ciudad de Buenos Aires (90\% de cobertura); habría tenido 14 años (Figura 13).

- Carlos, 72 años (a principios de 2016), recuerda haberlo visto desde el sur del Gran Buenos Aires ( $80 \%$ de cobertura); habría tenido 8 años (Figura 13).

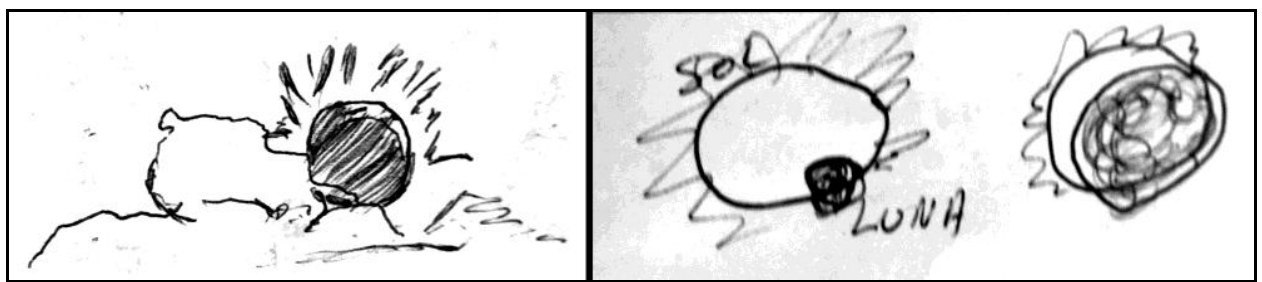

Figura 13 - Recuerdos de la observación de un mismo eclipse desde casi la misma ubicación geográfica (Héctor, izq., Ciudad de Buenos Aires y Carlos, der., Gran Buenos Aires).

Nótese el parecido entre ambos dibujos.

Ubicados todos ellos en un mapa de Argentina junto con la banda de anularidad, se pueden ver también aquí las distintas zonas desde las que aquellos chicos, hoy adultos mayores, observaron el eclipse anular en 1952 (Figura 14). 


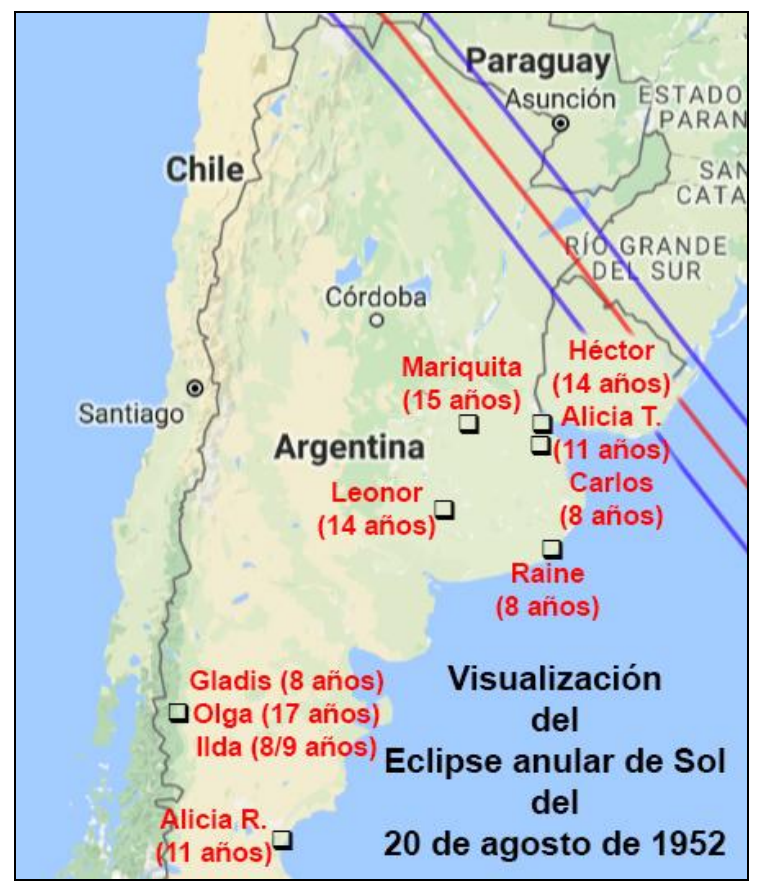

Figura 14 - El eclipse anular de 1952 visto por muchos chicos de Argentina.

Fuente: Captura de pantalla, luego editada, tomada de (NASA, 2017).

Si bien el eclipse anular de 1952 fue motivo de expediciones y otros estudios, se le dio menor trascendencia porque no se vería la corona, y los estudios de tipo astrométrico no tendrían tanta relevancia como en el eclipse total de 1947, sumado a esto que la región del país en la que se vería la anularidad era relativamente más pequeña y ubicada casi en el extremo norte del territorio nacional. (ASOCIACIÓN ARGENTINA AMIGOS DE LA ASTRONOMÍA, 1952).

Es de suponer, de todos modos, que los medios de difusión de la época habrían presentado esta noticia y que por consiguiente escuelas y familias habrán estado informadas de su ocurrencia, nótese que desde absolutamente todo el país el eclipse fue visible, al menos como parcial (Figura 15).

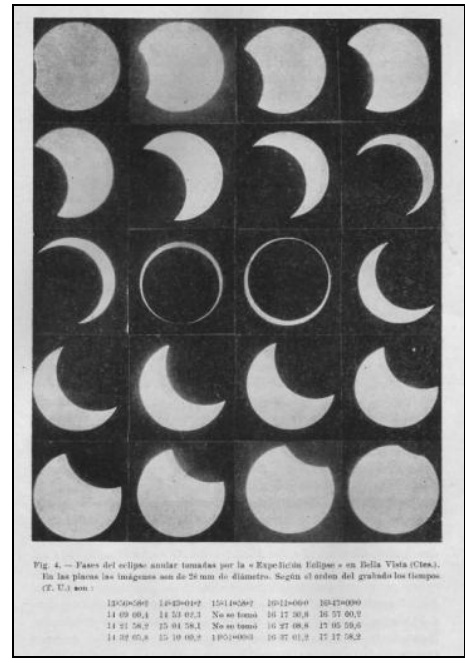

Figura 15 - Registro fotográfico del eclipse anular del 20 de agosto de 1952 desde Bella Vista, Corrientes.

Fuente: Revista Astronómica, n. 131, 1952. 


\section{Conclusiones}

Fue nuestra intención con el presente trabajo, en particular a través del cuestionario administrado, recuperar recuerdos de adultos mayores asociados a eclipses de Sol, que los mismos pudieran haber vivido cuando chicos. Nos preocupaba especialmente recuperar algunos aspectos esenciales, los que luego nos permitirían interpretar si los recuerdos relevados podrían identificarse, con cierto rango de incerteza aceptada, con eclipses de Sol visualizados desde Argentina en el período 1921-1960. Así, la localización de dónde estaba la persona cuando vio el eclipse, su edad en ese momento, la época del año y quizás el momento del día, con quiénes compartió la visualización, la duración del fenómeno, sus sentimientos asociados al suceso, y cualquier otro detalle relacionado (luminosidad del ambiente, comportamiento de los animales, creencias asociadas a los eclipses, etc.), fueron datos de gran importancia.

Consideramos importante explicitar aún más, en este momento, algunos detalles sobre los criterios utilizados en nuestro trabajo, en especial para que el Lector comprenda mejor "lo que no es", lo que no buscamos con el presente estudio, para focalizar entonces su atención sobre los logros del mismo y el valor de su proyección.

Hemos entrevistado a muchos otros adultos mayores, de diferentes rangos de edades hasta bien entrados los 90 años. Muchos de ellos no recuerdan nada asociado a eclipses de Sol; algunos afirman que no vieron ninguno y otros que no tienen ningún tipo de recuerdo asociado a estos fenómenos, por difusos o indirectos que estos fueran.

Por otra parte, vale recordar además que no hemos tenido en cuenta las condiciones meteorológicas de cada lugar en los distintos eclipses analizados, ya que sería muy posible que nubes, lluvia, etc., hubieran impedido la visualización de estos fenómenos aun habiendo estado informados de los mismos (intentar recuperar hoy día tales registros excede ampliamente nuestras posibilidades y objetivos).

Si bien hemos contactado a más de doscientos adultos mayores en aproximadamente doce años, en distintas regiones, los registros que hemos obtenido mostrando algún tipo de recuerdo concreto y específico son la minoría: iii no todo el mundo tiene que haber visto un eclipse de Sol !!!

El presente trabajo no busca establecer una estadística, de ningún modo. Nuestro interés fue identificar recuerdos en adultos mayores, de eclipses vividos hace muchas décadas, y que los relatos recogidos puedan rastrearse y vincularse lo más fielmente posible con el hecho astronómico específico, en tiempo, lugar y características. Este no es un trabajo sobre Psicología Cognitiva en lo que refiere a Memoria y a sus características a través del ciclo vital, sino que es una investigación cualitativa que busca dar valor a lo vivencialmente significativo que debe haber sido una visualización de un eclipse de Sol como para que su recuerdo haya perdurado durante décadas, y reflexionar sobre de qué manera a través de la Didáctica de la Astronomía podríamos en la actualidad generar acciones que generen un efecto similar en quienes hoy son niños, pensando en que tal vivencia los acompañe por toda la vida, en especial hasta cuando ellos mismos sean viejos y recuerden y compartan con muchos otros lo vivido.

Luego del estudio realizado, hemos mostrado a través de la transcripción de los relatos y de la posterior discusión de los datos construidos, que los adultos mayores 
entrevistados han recuperado recuerdos con gran precisión espacio-temporal y con detalles sorprendentes de eclipses que ellos mismos cuando chicos pudieron observar.

Desde nuestra concepción, entonces, y corroborando la hipótesis del presente trabajo, podemos afirmar que tales recuerdos remiten a experiencias vivencialmente significativas, algunas vividas hace más de medio siglo, con un muy importante ajuste a los hechos astronómicos propiamente dichos (lo que asegura, en alguna medida, que tales relatos no son fruto de falsos recuerdos autobiográficos (BERSTEIN et al, 2009)), con una fuerte vinculación afectiva y social (familia, compañeros, etc.), y una adecuada contextualización ambiental (escuela, campo, hogar, barrio, etc.).

Asumimos en la anterior afirmación que las incertezas en los relatos con respecto a los sucesos astronómicos concretos (en cuanto a los tiempos y espacios en que ocurrió lo que describen, en cuanto a la propia fenomenología de lo que recuerdan), es un valor de este estudio más que una falla metodológica.

Los registros que hemos obtenido remiten a recuerdos personales, individuales: aquellos eclipses fueron vividos por chicos, junto con otras personas, pero las entrevistas se responden desde el recuerdo que hoy pudieron recuperar a partir de la propuesta que les hicimos. Todos quienes han formado parte de este estudio, cuando fueron chicos mirando un eclipse solar no se conocían, no formaban un grupo unido por la maravilla de un eclipse de Sol (tenían distintas edades, vivían en diferentes lugares). Sin embargo, y en forma casi metafórica, podríamos afirmar hoy que "algo los une": la experiencia vivencialmente significativa de haber observado un eclipse de Sol cuando eran chicos. Y ese recuerdo los ha acompañado a través de su ya larga vida, un recuerdo hermoso, profundo, unido al cielo (TRIARHOU y DEL CERRO, 2007).

La mayoría de los adultos mayores que participaron de este estudio hace décadas que viven en la Patagonia, eso también los une. Qué interesante sería reunir a todos quienes compartieron un eclipse cuando chicos, para que hoy cuando viejos conversaran entre ellos sobre sus recuerdos, y así construir una especie de "memoria colectiva", a partir de los recuerdos comunes, socializados (OLIVEIRA FRANÇA, 2009). Jamás una experiencia individual, una mirada subjetiva, cubre la totalidad de aspectos físicos y vivenciales de un suceso, astronómico en este caso; si bien su valor es de gran riqueza no es único ni suficiente, sólo la mirada compartida que construye una mirada social nos cuenta la historia de ese momento (¿¿cuántas miradas más habrá entre los adultos mayores con quienes convivimos hoy?!).

Cuando una experiencia es novedosa y emocionalmente excitante, es muy probable que sea recuperado su recuerdo a lo largo de la vida y con gran detalle; si bien tales eventos se dan muy de vez en cuando, si su carga emocional es suficientemente fuerte la gente lo recordará: la visualización de eclipses de Sol es de esa clase de experiencias (es claro que si los eclipses solares ocurrieran y además pudieran verse todos los meses, la carga emocional de los mismos se reduciría sustancialmente, y nadie los recordaría como algo excitante a lo largo de las décadas de su propia vida) (WHITEHOUSE, 2005). La acción educativa intencional fortaleciendo aquellos aspectos de la visualización de un eclipse de Sol es lo que, además, la convierte en vivencialmente significativa: no sólo se aprende, se comparte, se emociona, sino que además, y quizás por todo esto, se integra en la propia estructura de la memoria para toda la vida. 


\section{Comentario final}

Estamos convencidos de que, en nuestra tarea dentro del gran campo de la Enseñanza de la Astronomía, en sus múltiples formas, no sólo debemos tender a la construcción de aprendizajes significativos, sino buscar que además tales aprendizajes sean también vivencialmente significativos.

Debemos transformar un hecho natural, un eclipse de Sol, en más que un objeto de estudio para el aprendizaje de ciertos conceptos y métodos de la Astronomía y de la Cultura, sino que además sea una situación que nos emocione, involucrando a las familias y amigos en el proceso de observación y posterior trabajo "científico", dando a conocer lo que han hecho y sentido a otros ámbitos fuera de la propia escuela o grupo de pertenencia, relatando no sólo la memoria del proceso educativo-científico sino también las emociones y representaciones asociadas con la totalidad de la experiencia.

Por esto, quienes nos dedicamos a la Enseñanza de la Astronomía debemos planificar a futuro, con mucho tiempo, preparándonos para lo que vendrá, entrando en el ritmo de los diversos aspectos astronómicos de la naturaleza, compartiendo la experiencia, aprendiendo unos de otros, todos aprendices en definitiva, fortaleciendo un vínculo social a través de las experiencias del cielo. Oportunidades no nos faltan...

Hay muchos viejos a nuestro alrededor que pueden contarnos de qué manera vivieron cuando chicos la observación de eclipses de Sol, aquellos de un tiempo en el que se vivía diferente, en que no existían los recursos tecnológicos de hoy, en que la comunicación era más lenta y no necesariamente apoyada en la imagen, y en que el cielo era visto como motivo de asombro, respeto y búsqueda (características que en buena medida aún se mantienen en nuestro presente). ¿Quiénes escucharán sus relatos? Quizás un buen momento será compartir los eclipses de Sol que vendrán junto con ellos, compartiendo las emociones y preguntas de los chicos, los de ahora y los de antes.

El 26 de febrero de 2017 sucedió un eclipse anular de Sol, visible desde el sur de la provincia del Chubut. Los Autores hemos participado de diversas actividades en la región patagónica, organizando en particular el Segundo Workshop de Difusión y Enseñanza de la Astronomía ${ }^{3}$, realizado en Esquel desde el 22 al 24 de febrero, y coordinando luego la observación de la anularidad desde la localidad de Facundo, además de proveer información y brindar elementos para la observación en el resto de la región, desde donde se lo pudo observar como parcial. Muchos de los adultos mayores que nos han brindado sus recuerdos para el presente trabajo observaron este eclipse, algunos acompañados por sus nietos, y muchos otros chicos habrán observado este eclipse con una intensidad, compañía y participación que, así lo esperamos y deseamos, les brindarán elementos para construir entre todos una vivencia que se convertirá en un recuerdo profundo en sus vidas (Figuras 16 y 17).

En los próximos años se podrán ver desde Argentina (y América del Sur) los siguientes eclipses de Sol:

- 15 de febrero de 2018 (parcial).

- 2 de julio de 2019 (total, visible desde el centro norte de Argentina), que coincidirá con el centenario del célebre eclipse de 1919 en el que se corroboró por primera vez uno de los postulados de la Teoría de la Relatividad.

\footnotetext{
${ }^{3}<$ http://sion.frm.utn.edu.ar/WDEAII $>$.
} 
- 14 de diciembre de 2020 (total, visible desde Patagonia).

- 30 de abril de 2022 (parcial).

- 14 de octubre de 2023 (anular, visible como parcial en Argentina y como anular en Brasil y Colombia).

- 2 de octubre de 2024 (anular, visible desde Patagonia).

- 17 de febrero de 2026 (anular, poco visible como parcial desde el extremo sur de la Patagonia).

- 6 de febrero de 2027 (anular, visible desde Patagonia y Uruguay).

- 26 de enero de 2028 (anular, visible como parcial en Argentina, como anular en Brasil, Ecuador y Perú).

- 11 de julio de 2029 (parcial).

Como astrónomos profesionales y amateurs, divulgadores y educadores, es de alguna manera nuestra responsabilidad la de generar acciones didácticas específicas a partir de estas oportunidades que tendremos en el futuro con la ocurrencia de los eclipses antes citados, para que todos, chicos y grandes, observemos, comprendamos y nos emocionemos viviendo la experiencia de compartir con otros un eclipse solar, construyendo así los recuerdos que nos acompañarán por el resto de nuestro ciclo vital, convirtiéndose también en memoria colectiva del grupo de pertenencia.

Para las acciones didácticas que deberemos diseñar para los eclipses de Sol que vendrán, es casi una obviedad buscar que la calidad (conceptual, metodológica) de las distintas propuestas didácticas que se diseñen para su observación esté asegurada, pero no lo es recomendar que incorporemos a los más viejos en todas las actividades que pongamos en práctica, escucharlos y vincularlos afectivamente con los más chicos, escuchando las historias de unos y otros, relatos de momentos de la vida de cada quien ante un fenómeno que nos conmueve.

Replicar el presente trabajo en otras regiones de nuestra América del Sur brindaría seguramente elementos muy interesantes, dada la diversidad cultural que nos es propia. ¡iTenemos aún mucho y buen trabajo por hacer!!

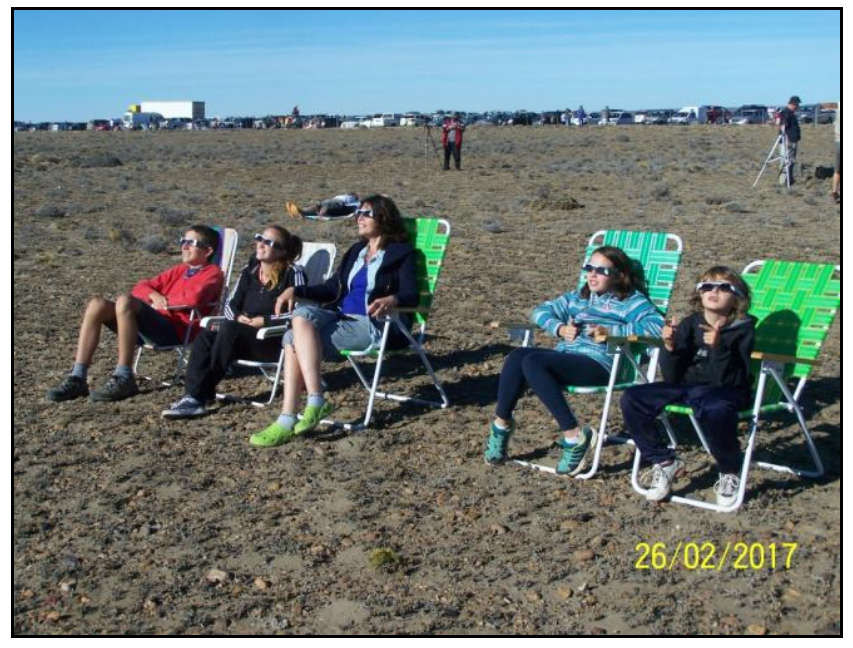

Figura 16 - Varios chicos y la mamá de dos de ellos observando el eclipse anular de Sol desde Facundo, Chubut.

Fuente: de los Autores. 


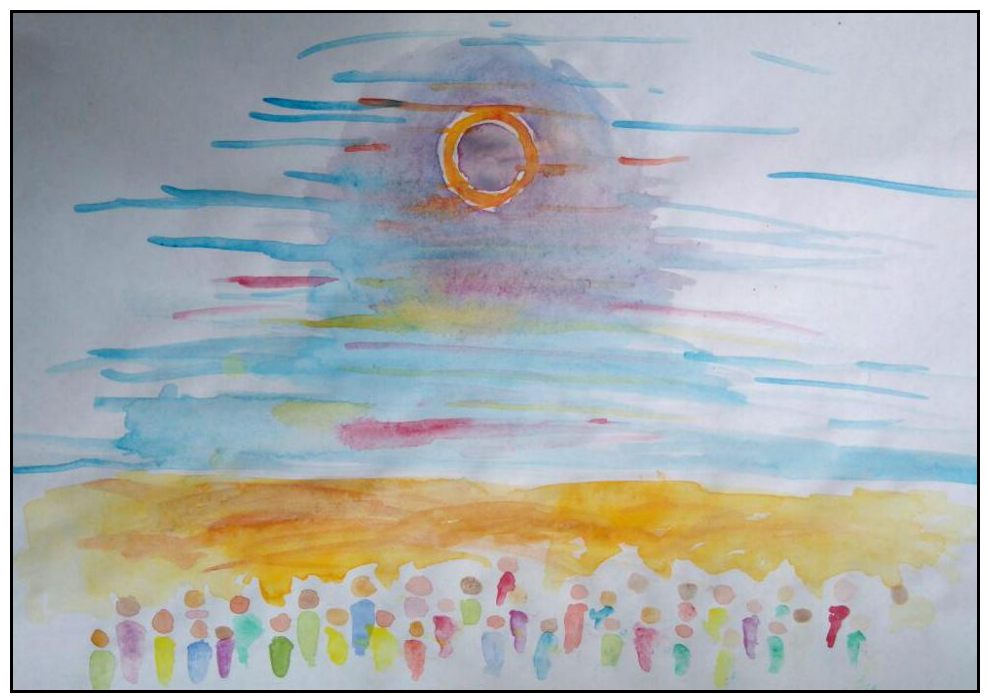

Figura 17 - Dibujo realizado por Marcos (12 años), poco después de la observación del eclipse anular del 26 de febrero de 2017 en Facundo, Chubut.

Fuente: de los Autores.

\section{Agradecimientos}

Los Autores agradecemos a todas las personas que de una manera u otra nos han ayudado en la realización del presente trabajo, en especial a los muchos viejos que se esforzaron en recuperar sus recuerdos, a veces reviviendo emociones muy fuertes, permitiendo generosamente que los utilizáramos para construir una particular historia de la visualización de eclipses de Sol en nuestro país.

\section{Referencias}

ASOCIACIÓN ARGENTINA AMIGOS DE LA ASTRONOMÍA. Revista Astronómica, n.118-121, 130, 131, 1947 e 1952.

BALLARINI, Fabricio. REC. Editorial Sudamericana, Buenos Aires, Argentina, 2014. BERSTEIN, Daniel; GODFREY, Ryan; LOFTUS, Elizabeth. False memories: the role and plausibility and autobiographical belief. In.: MARKMAN, K.; KLEIN, W.; SUHR, J. (Eds.). Hanbook of Imagination and Mental Simulation. Psych., 2009. p.89-102.

CAMINO, Néstor; et al. El Proyecto Chiron, una mirada al cielo que todos llevamos dentro y que creíamos olvidado. Revista Desde la Patagonia: Difundiendo saberes. v.6, n.9, p.56-63, 2009.

HENIGE, David. Day was of sudden turned into night: On the Use of Eclipses for Dating Oral History. Comparative Studies in Society and History, v.18, n.4, p.476501, 1976.

IGOA, José Manuel. Memoria y relato. Arbor, CLXVII, p.105-123, 2004.

NASA/GSFC. Five Millennium Catalog of Solar Eclipses: (1901 CE to $2000 \mathrm{CE}$ ). Disponible en: <https://eclipse.gsfc.nasa.gov/SEcat5/SE1901-2000.html>. Recuperado el: 30/09/2017. 
NASA/GSFC. Key to solar eclipse global maps. Disponible en:

<https://eclipse.gsfc.nasa.gov/OH/SEplotkey.html>. Recuperado el: 30/09/2017.

OLIVEIRA FRANÇA, Renné. Eclipses do Inesquecível: o papel da memória na contemporaneidade a partir da Retrospectiva de Final de Ano. Anuário Internacional de Comunicação Lusófona, p.115-132, 2009.

ORIOLA, Jorge. Esquel, medio siglo de crecimiento y periodismo entre 1924 y 1960.

En Patagonia Data Base, de Ricardo E. Drault. 2017 Disponible en:

<www.drault.com/pdb/esquel/esquel-indice.html>. Recuperado el: 30/09/2017.

PAOLANTONIO, Santiago. Eclipse total de Sol de 1947: Sobre las expediciones realizadas por el ONA para la observación del eclipse total de sol de 1947. 2011. Disponible en: <http://historiadelaastronomia.wordpress.com/documentos/eclipse 1947>. Recuperado el: 30/09/2017.

PRINS, Gwyn. Historia Oral. Historia y Fuente Oral, n.9, p.21-43, 1993. Disponible en: <http://www.jstor.org/stable/27753385>. Recuperado el: 30/09/2017.

TRIARHOU, Lazaros; DEL CERRO, Manuel. Cajal on Solar Eclipse. European Neurology, p. 108-111, 2007.

WHITEHOUSE, Harvey. Emotion, Memory and Religious Rituals: An Assessment of Two Theories. In.: MILTON, Kay; SVASEK, Maruska (Eds.). Mixed Emotions.

Oxford: Berg, 2005. p.91-108.

ANEXO A - Datos de los eclipses de Sol visibles desde Argentina desde 1921 a 1960.

Fuente: NASA. Eclipse Web Site. Disponible en:

<https://eclipse.gsfc.nasa.gov/SEcat5/SE1901-2000.html>. Recuperado el: 30/09/2017.

\begin{tabular}{|c|c|c|c|c|c|c|}
\hline \multicolumn{7}{|c|}{ Solar Eclipses: 1921 - 1930} \\
\hline $\begin{array}{l}\text { Calendar } \\
\text { Date }\end{array}$ & $\begin{array}{l}\text { TD of } \\
\text { Greatest } \\
\text { Eclipse }\end{array}$ & $\begin{array}{l}\text { Eclipse } \\
\text { Type }\end{array}$ & $\begin{array}{l}\text { Saros } \\
\text { Series }\end{array}$ & $\begin{array}{c}\text { Eclipse } \\
\text { Magnitude }\end{array}$ & $\begin{array}{c}\text { Central } \\
\text { Duration }\end{array}$ & Geographic Region of Eclipse Visibility \\
\hline $\begin{array}{l}\text { (Link to } \\
\text { Global Map) }\end{array}$ & & $\begin{array}{l}\text { (Link to } \\
\text { Google } \\
\text { Map) }\end{array}$ & $\begin{array}{l}\text { (Link to } \\
\text { Saros) }\end{array}$ & & $\begin{array}{l}\text { (Link to } \\
\text { Path Table) }\end{array}$ & \\
\hline 1921 Oct 01 & $12: 35: 58$ & $\underline{\text { Total }}$ & $\underline{123}$ & 1.029 & $\underline{01 \mathrm{~m} 52 \mathrm{~s}}$ & $\begin{array}{l}\text { Antarctica, s S America } \\
\text { [Total: Antarctica] }\end{array}$ \\
\hline 1922 Mar 28 & $13: 05: 26$ & $\underline{\text { Annular }}$ & $\underline{128}$ & 0.938 & $\underline{07 \mathrm{~m} 50 \mathrm{~s}}$ & $\begin{array}{l}\text { e S America, Carribean, n Africa, Europe, w Asia } \\
\text { [Annular: Peru, Brazil, Senegal, Mali, Mauritania, } \\
\text { Algeria, Libya, Egypt, Saudi Arabia] }\end{array}$ \\
\hline 1923 Mar 17 & $12: 44: 58$ & $\underline{\text { Annular }}$ & $\underline{138}$ & 0.931 & $\underline{07 \mathrm{~m} 51 \mathrm{~s}}$ & $\begin{array}{l}\text { s S America, s Africa, Antarctica } \\
\text { [Annular: Chile, Argentina, Nambia, Botswana, } \\
\text { Zimbabwe, Mozambique, Madagascar] }\end{array}$ \\
\hline$\underline{1927 \text { Jan } 03}$ & $20: 22: 54$ & $\underline{\text { Annular }}$ & $\underline{140}$ & 0.999 & $\underline{00 \mathrm{~m} 03 \mathrm{~s}}$ & $\begin{array}{l}\text { Antarctica, N.Z., sw S America } \\
\text { [Annular: New Zealand, Chile, Argentine, } \\
\text { Uruguay, Brazil] }\end{array}$ \\
\hline 1928 May 19 & $13: 24: 20$ & $\underline{\text { Total }}$ & $\underline{117}$ & 1.014 & - & $\begin{array}{l}\text { Antarctica, s S America, s Africa } \\
\text { [Total: South Atlantic] }\end{array}$ \\
\hline 1930 Oct 21 & $21: 43: 54$ & Total & $\underline{142}$ & 1.023 & $\underline{01 \mathrm{~m} 55 \mathrm{~s}}$ & $\begin{array}{l}\text { Australia, New Guinea, New Zealand } \\
\text { [Total: South Pacific] }\end{array}$ \\
\hline
\end{tabular}




\begin{tabular}{|c|c|c|c|c|c|c|}
\hline \multicolumn{7}{|c|}{ Solar Eclipses: 1931 - 1940} \\
\hline \multirow{2}{*}{$\begin{array}{l}\text { Calendar } \\
\text { Date } \\
\text { (Link to } \\
\text { Global Map) }\end{array}$} & \multirow[t]{2}{*}{$\begin{array}{l}\text { TD of } \\
\text { Greatest } \\
\text { Eclipse }\end{array}$} & \multirow{2}{*}{$\begin{array}{l}\text { Eclipse } \\
\text { Type } \\
\text { (Link to } \\
\text { Google } \\
\text { Map) }\end{array}$} & \multirow{2}{*}{$\begin{array}{l}\text { Saros } \\
\text { Series } \\
\text { (Link to } \\
\text { Saros) }\end{array}$} & \multirow[t]{2}{*}{$\begin{array}{l}\text { Eclipse } \\
\text { Magnitude }\end{array}$} & \multirow{2}{*}{$\begin{array}{c}\begin{array}{c}\text { Central } \\
\text { Duration }\end{array} \\
\text { (Link to } \\
\text { Path Table) }\end{array}$} & \multirow[t]{2}{*}{ Geographic Region of Eclipse Visibility } \\
\hline & & & & & & \\
\hline 1931 Oct 11 & $12: 55: 40$ & Partial & $\underline{152}$ & 0.901 & - & s S America, Antarctica \\
\hline 1933 Feb 24 & 12:46:39 & Annular & $\underline{129}$ & 0.984 & $\underline{01 \mathrm{~m} 32 \mathrm{~s}}$ & $\begin{array}{l}\text { s S America, Africa, Antarctica } \\
\text { [Annular: Chile, Argentina, Congo, Zaire, C.A.R., } \\
\text { Sudan, Ethiopia, Djibouti, Yemen] }\end{array}$ \\
\hline 1935 Dec 25 & $17: 59: 52$ & $\underline{\text { Annular }}$ & $\underline{121}$ & 0.975 & $\underline{01 \mathrm{~m} 30 \mathrm{~s}}$ & $\begin{array}{l}\text { Antarctica, s S America } \\
\text { [Annular: Antarctica] }\end{array}$ \\
\hline 1936 Dec 13 & 23:28:12 & $\underline{\text { Annular }}$ & $\underline{131}$ & 0.935 & $\underline{07 \mathrm{~m} 25 \mathrm{~s}}$ & $\begin{array}{l}\text { Australia, Antarctica, New Zealand } \\
\text { [Annular: Australia, New Zealand] }\end{array}$ \\
\hline 1937 Jun 08 & $20: 41: 02$ & Total & $\underline{136}$ & 1.075 & $\underline{07 \mathrm{~m} 04 \mathrm{~s}}$ & $\begin{array}{l}\text { s N America, C America, nw S America } \\
\text { [Total: central Pacific, Peru] }\end{array}$ \\
\hline 1938 May 29 & 13:50:19 & $\underline{\text { Total }}$ & $\underline{146}$ & 1.055 & $\underline{04 \mathrm{~m} 05 \mathrm{~s}}$ & $\begin{array}{l}\text { s S America, s Africa } \\
\text { [Total: South Atlantic] }\end{array}$ \\
\hline 1939 Oct 12 & $20: 40: 24$ & $\underline{\text { Total }}$ & $\underline{123}$ & 1.027 & $\underline{01 \mathrm{~m} 32 \mathrm{~s}}$ & $\begin{array}{l}\text { Antarctica, Australia, s S America, N.Z. } \\
\text { [Total: Antarctica] }\end{array}$ \\
\hline 1940 Oct 01 & 12:44:06 & $\underline{\text { Total }}$ & $\underline{133}$ & 1.064 & $\underline{05 \mathrm{~m} 35 \mathrm{~s}}$ & $\begin{array}{l}\text { S America, s Africa } \\
\text { [Total: Colombia, Venezuela, Brazil, South Africa] }\end{array}$ \\
\hline
\end{tabular}

NATIONAL AERONAUTICS
AND SPACE ADMINISTRATION
EXPLORE. DISCOVER. UNDERSTAND.

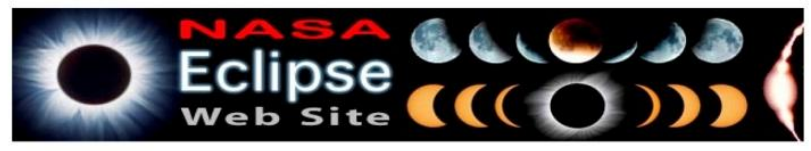

\begin{tabular}{|c|c|c|c|c|c|c|}
\hline \multicolumn{7}{|c|}{ Solar Eclipses: 1941 - 1950} \\
\hline $\begin{array}{l}\text { Calendar } \\
\text { Date }\end{array}$ & $\begin{array}{l}\text { TD of } \\
\text { Greatest } \\
\text { Eclipse }\end{array}$ & $\begin{array}{c}\text { Eclipse } \\
\text { Type }\end{array}$ & $\begin{array}{l}\text { Saros } \\
\text { Series }\end{array}$ & $\begin{array}{c}\text { Eclipse } \\
\text { Magnitude }\end{array}$ & $\begin{array}{c}\text { Central } \\
\text { Duration }\end{array}$ & Geographic Region of Eclipse Visibility \\
\hline $\begin{array}{l}\text { (Link to } \\
\text { Global Map) }\end{array}$ & & $\begin{array}{l}\text { (Link to } \\
\text { Google } \\
\text { Map) }\end{array}$ & $\begin{array}{l}\text { (Link to } \\
\text { Saros) }\end{array}$ & & $\begin{array}{l}\text { (Link to } \\
\text { Path Table) }\end{array}$ & \\
\hline 1941 Mar 27 & 20:08:08 & Annular & $\underline{138}$ & 0.935 & $\underline{07 \mathrm{~m} 41 \mathrm{~s}}$ & $\begin{array}{l}\text { Antarctica, S America, C America } \\
\text { [Annular: South Pacific, Peru, Bolivia, Brazil] }\end{array}$ \\
\hline 1944 Jan 25 & $15: 26: 42$ & Total & $\underline{130}$ & 1.043 & $\underline{04 \mathrm{~m} 09 \mathrm{~s}}$ & $\begin{array}{l}\text { S America, C America, w Africa } \\
\text { [Total: Peru, Brazil, Sierra Leone, Guinea, Mali, } \\
\text { Niger] }\end{array}$ \\
\hline 1946 Jan 03 & 12:16:11 & Partial & $\underline{150}$ & 0.553 & - & s S America, Antarctica \\
\hline 1946 May 30 & 21:00:24 & Partial & $\underline{117}$ & 0.886 & - & South Pacific \\
\hline 1947 May 20 & 13:47:47 & Total & $\underline{127}$ & 1.056 & $\underline{05 \mathrm{~m} 13 \mathrm{~s}}$ & $\begin{array}{l}\text { S America, Africa } \\
\text { [Total: Chile, Argentina, Paraguay, Brazil, central } \\
\text { Africa] }\end{array}$ \\
\hline 1947 Nov 12 & 20:05:37 & Annular & $\underline{132}$ & 0.965 & $\underline{03 \mathrm{~m} 59 \mathrm{~s}}$ & $\begin{array}{l}\text { N \& S America } \\
\text { [Annular: central Pacific, Peru, Ecuador, } \\
\text { Colombia Brazil] }\end{array}$ \\
\hline 1950 Mar 18 & 15:32:02 & Annular & $\underline{119}$ & 0.962 & - & $\begin{array}{l}\text { s Africa, s S America, Antarctica } \\
\text { [Annular: Antarctica] }\end{array}$ \\
\hline
\end{tabular}


Eclipses de cuando éramos chicos: recuerdos vivencialmente significativos de eclipses de Sol

NATIONAL AERONAUTICS

AND SPACE ADMINISTRATION

EXPLORE. DISCOVER. UNDERSTAND.

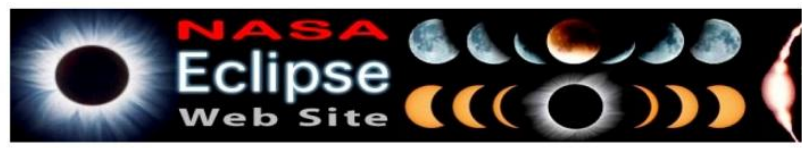

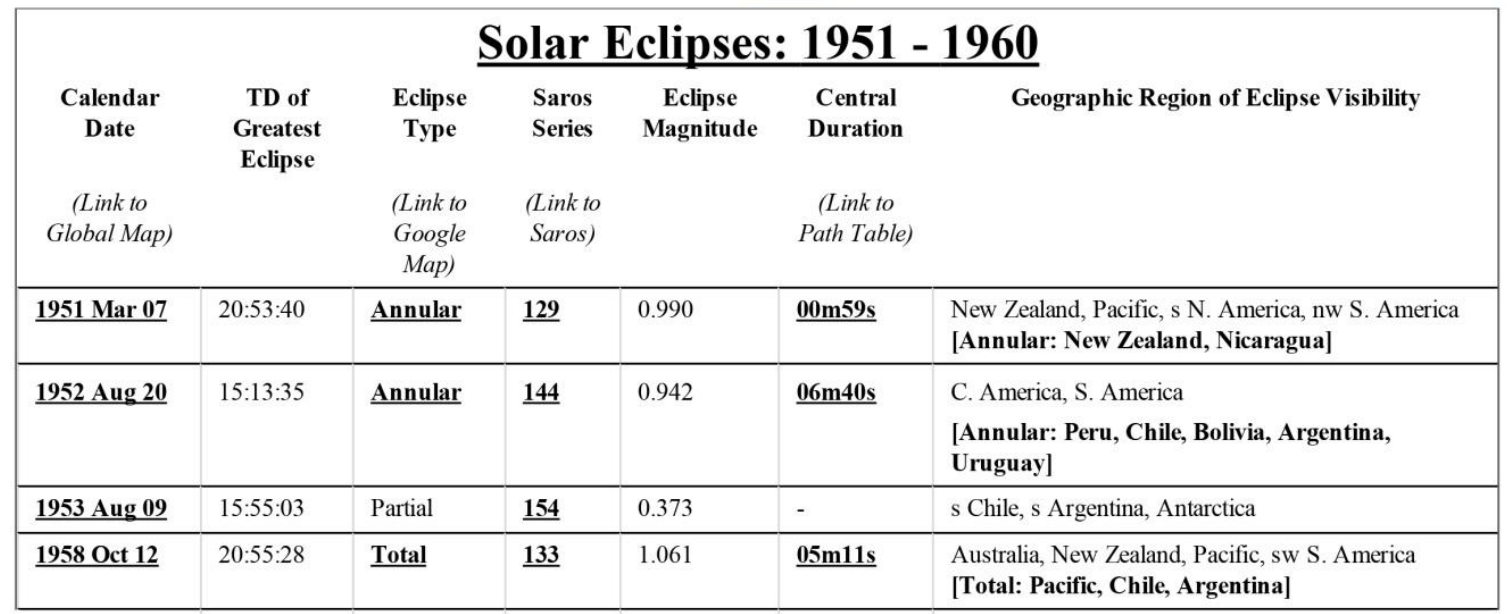

